\title{
Finite-Element Electroacoustic Analysis and Taguchi Design of Piezoelectric Buzzers Based on the Vibration Absorber Model
}

\author{
Mingsian R. Bai ${ }^{*},{ }^{1}$, Rong-Liang Chen ${ }^{1}$, Chung-Yuan Chuang ${ }^{1}$, Cheng-Sheng $\mathrm{Yu}^{2}$ and \\ Huey-Lin $\mathrm{Hsieh}^{2}$ \\ ${ }^{I}$ Department of Mechanical Engineering, National Chiao-Tung University, 1001 Ta-Hsueh Road, Hsin-Chu 300, \\ Taiwan \\ ${ }^{2}$ Ceramic Materials Section, New Materials Research \& Development Department, China Steel Corporation, 1 Chung \\ Kang Road, Hsiao Kang, Kaohsiung 812, Taiwan
}

\begin{abstract}
Lumped parameter models of piezoelectric buzzers are established with finite element-based electroacoustic parameter identification procedures. The analysis starts with modeling the diaphragm structure by using finite element method (FEM). The FEM model is then converted into electro-mechanical two-ports to fit into the electro-mechanoacoustical (EMA) analogous circuit. Electrical impedance of the piezoelectric diaphragm is simulated using the model. An 'added-mass' method is developed to identify the lumped parameters. Electrical impedance and on-axis sound pressure level (SPL) of a piezoelectric buzzer (containing the diaphragm and case) can be simulated by solving the loop equations of the analogous circuits. On the basis of the model, optimal structural parameters and configurations for the buzzer can be found to maximize the sound pressure output, using the Taguchi method and constrained optimization. Simulation and experimental results showed that the performance has been significantly improved using the optimal design. Design guidelines for the piezoelectric buzzers are summarized.
\end{abstract}

\section{INTRODUCTION}

Piezoelectric transducers offer numerous advantages in high transduction efficiency, excellent ruggedness, fast response time, low form factor, high force output, precise positioning, free of electromagnetic interference, etc. Used as electroacoustic transducers, piezoelectric buzzer is one of the most commonly used devices that find applications in household appliances, car security systems, and medical apparatus, electronic toll collection (ETC) systems. A typical piezoelectric buzzer is comprised of a piezoelectric diaphragm, a cavity with a port, and electrode terminals, as shown in Fig. (1a-c). The piezoelectric diaphragm is generally made up of a piezoelectric ceramic disc attached to a slightly larger metal plate. They are essentially narrowband devices for operating at resonant frequencies to maximize sound pressure output. As simple as it may seem, rigorous analysis is necessary for establishing an accurate model on which a useful design can be realized. The purpose of this paper is twofold. First, an electroacoustic model is developed for fitting the finite element model (FEM) into the lumpedparameter circuit, using two-port theory. Second, an optimization procedure is presented for maximizing the sound pressure output at the pre-specified driving frequency.

Some studies on piezoelectric plate were reported in the past. Caliano et al. [1] proposed a piezoelectric bimorph membrane sensor for pressure measurement. Tseng and Liou

*Address correspondence to this author at the Department of Mechanical Engineering, National Chiao-Tung University, 1001 Ta-Hsueh Road, HsinChu 300, Taiwan; E-mail: msbai@mail.nctu.edu.tw
[2], Dobrucki and Pruchnicki [3], and Wang et al. [4] conducted theoretical and numerical investigations on the dynamic responses of bimorph piezoacoustic transducers. Wang et al. [5], Lim [6] and Guo et al. [7] modeled the piezoelectric transducer by the FEM. The dynamic behavior of the piezoelectric transducer was solved by FEM and compared to the results of experiment. Aronov [8,9] applied energy methods to analyze the piezoelectric transducers and established a model for simulation. Similar methodology was also applied to other piezoelectric transducers, e.g., panel speakers [10] and ultrasonic transducers [11,12] etc. Caronti et al. [12] modeled a capacitive micromachined ultrasonic transducer by a two-port network. Gallas et al. [13] used lumped-element models to examine the frequency responses of a piezoelectric-driven synthetic jet actuator. Bai et al. [14] suggested a design chart method and a constrained optimization approach for the design of piezoelectric buzzer.

In order to fulfill the first purpose of this paper, a simulation platform is developed for fitting the FEM model into the lumped-parameter circuit. The finite element analysis is carried out for only piezoelectric diaphragm (PZT and metal plate). The FEM model is then converted to a two-port [12] model that can readily fuse into electro-mechano-acoustical (EMA) $[15,16]$ analogous circuit of the system. An addedmass method similar to that used to electrodynamic loudspeakers is then used to determine lumped parameters $[15$, 16]. Next, a circuit of the complete buzzer system is constructed by combining the lumped parameter models of the diaphragm and the housing that includes a cavity and a port, with the interactions between the piezoelectric diaphragm and the housing taken into account. Electrical impedance and 
on-axis pressure response of the piezoelectric buzzer can be calculated by solving the loop equations [17] of the analogous circuit of the coupled system.

(a)

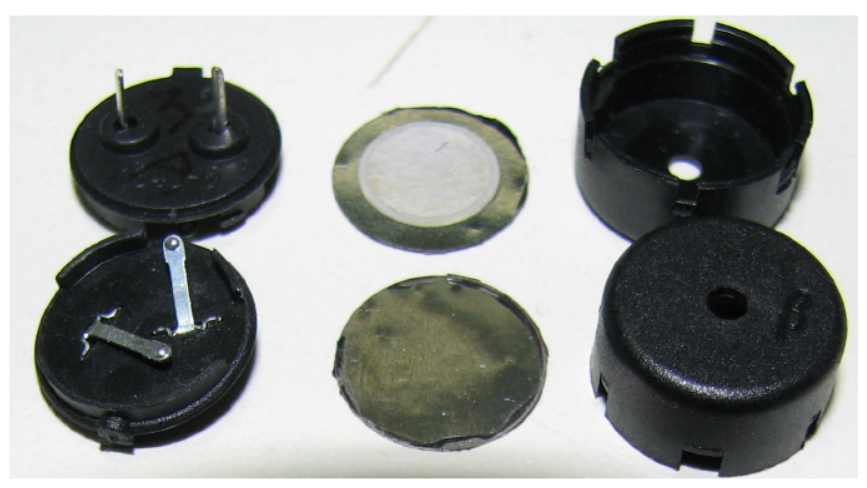

(b)
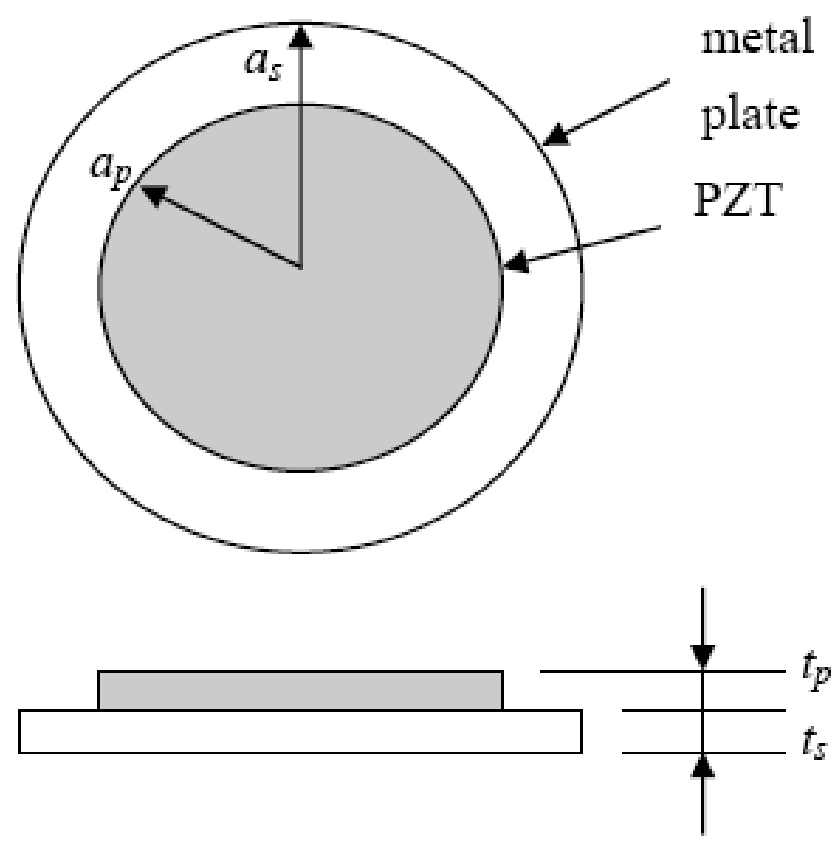

(c)

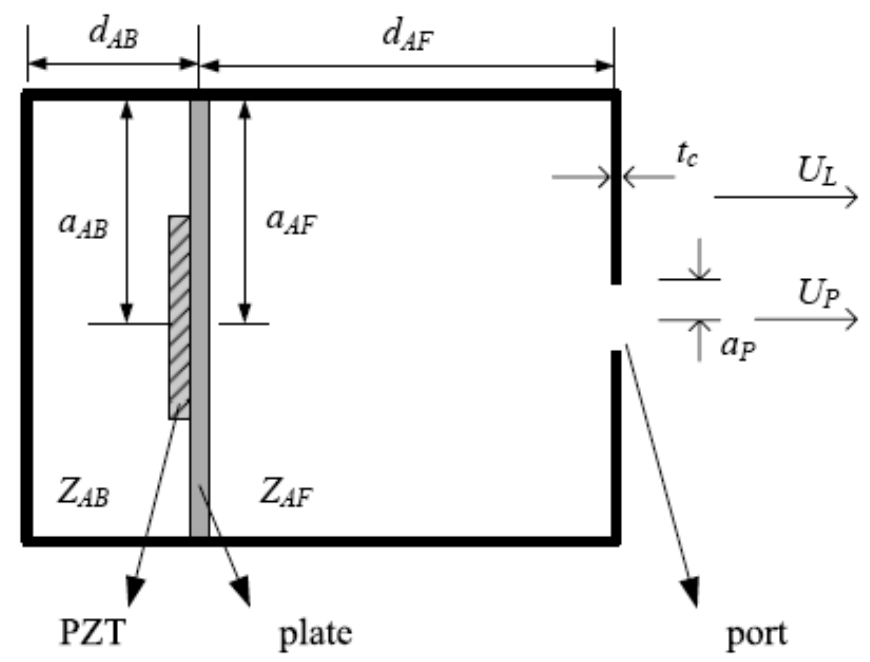

Fig. (1). Piezoelectric buzzer. (a) photo of the buzzer, (b) diaphragm structure, (c) cross-section of the piezoelectric buzzer.
On the basis of the established model, sensitivity analysis is conducted to examine the effects of varying physical parameters on the lumped parameters. In addition, an optimization procedure is developed in this paper. Unlike the previous work of Ref. [14] that utilizes constrained optimization, the present approach is based on a popular experimental design procedure, the Taguchi method [18]. As will be demonstrated by simulations and experiments, the optimized design significantly improves the performance of the buzzer over the original design. The physical insights as well as guidelines for design are summarized in the conclusion section.

\section{MODELING OF THE PIEZOELECTRIC BUZZER}

The following analysis of the piezoelectric buzzer includes two categories: the piezoelectric diaphragm and the acoustic cavity. A FEM-based two-port model will be constructed for the piezoelectric diaphragm, which will be combined with the acoustical model of the cavity and port system.

A practical sample of piezoelectric buzzer with a 12.7 $\mathrm{mm}$ diameter and $6 \mathrm{~mm}$ thickness is shown in Fig. (1a). The piezoelectric diaphragm is fitted in a plastic case. A pair of metal terminals are electrically connected to the piezoelectric diaphragm and drawn out from the back cover of the plastic case. The front portion of the buzzer consists mainly of a cavity and a port that serves as the sound outlet. The cross section of the piezoelectric buzzer is shown in Fig. (1b) with dimensions indicated in Table 1. Fig. (1c) shows the diaphragm that is comprised of a circular piezoelectric ceramic (lead zirconate titanate, PZT 5A) and a circular plate (Fe-Ni alloy, $\mathrm{Fe}-60 \%$, Ni-40\%). By comparing the electrical impedance of this piezoelectric diaphragm (Fig. 2a) and that of a rectangular plate of standard PZT 5A sample without the metal plate (Fig. 2b), we found that the piezoelectric diaphragm follows basically similar trend to that of a piezoelectric ceramic alone. This suggests that the piezoelectric diaphragm can be modeled in the low frequency regime by the same structure of the analogous circuit in Fig. $(\mathbf{3 a}, \mathbf{b})$, as that used for a pure PZT sample.

Table 1. The Dimensions of the Piezoelectric Buzzer

\begin{tabular}{|l|c|}
\hline \multicolumn{1}{|c|}{ Parameters } & Dimension (mm) \\
\hline \hline radius of rear cavity $\left(a_{A B}\right)$ & 5.000 \\
\hline depth of rear cavity $\left(d_{A B}\right)$ & 1.480 \\
\hline radius of front cavity $\left(a_{A F}\right)$ & 5.250 \\
\hline depth of front cavity $\left(d_{A F}\right)$ & 3.080 \\
\hline thickness of cavity $\left(t_{c}\right)$ & 0.760 \\
\hline radius of port $\left(a_{p}\right)$ & 1.065 \\
\hline radius of plate $\left(a_{s}\right)$ & 5.570 \\
\hline thickness of plate $\left(t_{s}\right)$ & 0.050 \\
\hline radius of PZT $\left(a_{p}\right)$ & 4.000 \\
\hline thickness of PZT $\left(t_{p}\right)$ & 0.090 \\
\hline
\end{tabular}


(a)

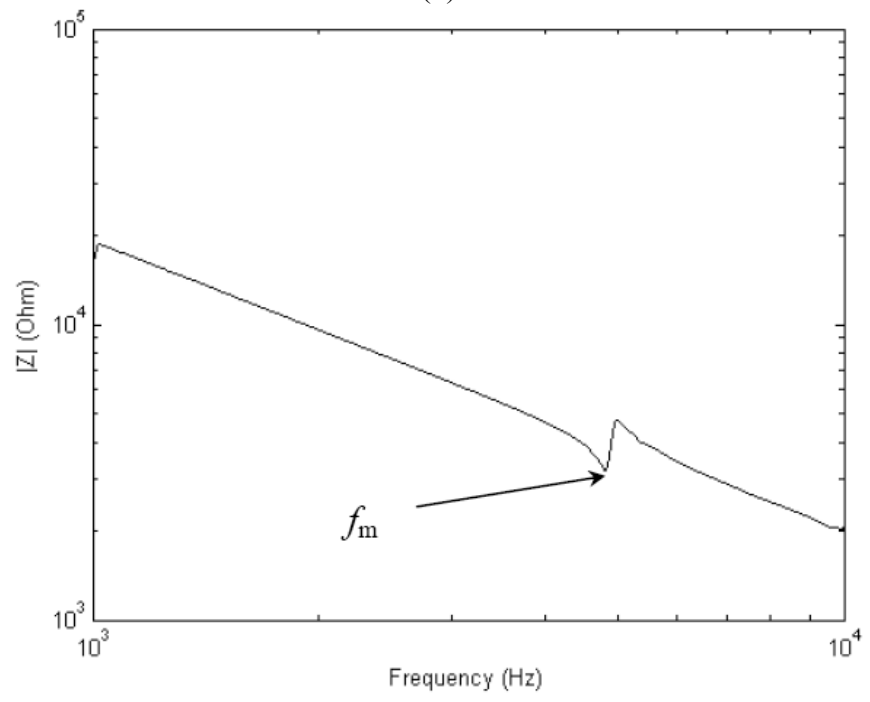

(b)

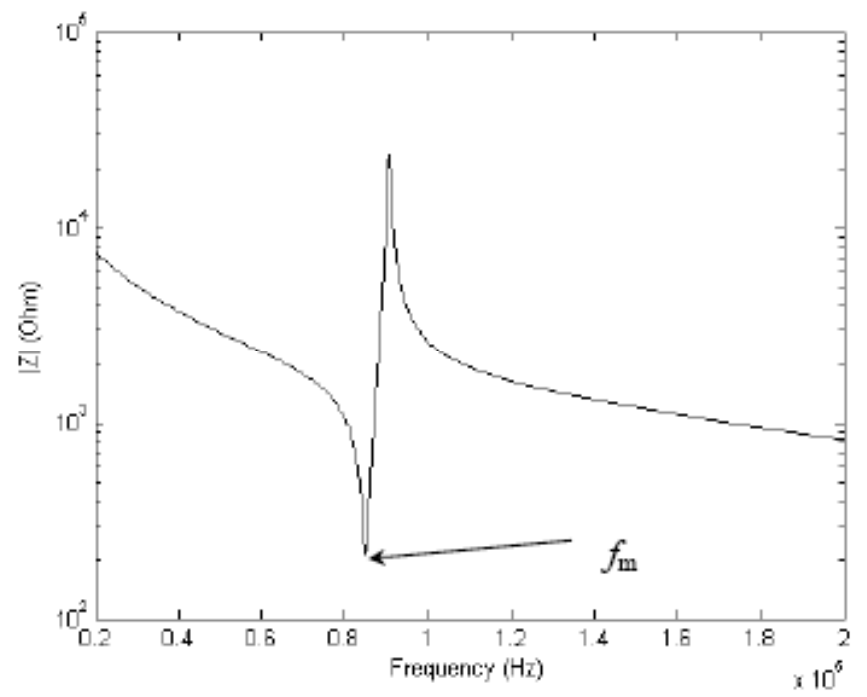

Fig. (2). The measured electrical impedance of piezoelectric samples. (a) piezoelectric diaphragm comprised of the PZT disc and the metal plate, (b) rectangular plate of a standard PZT 5A sample.

(a)

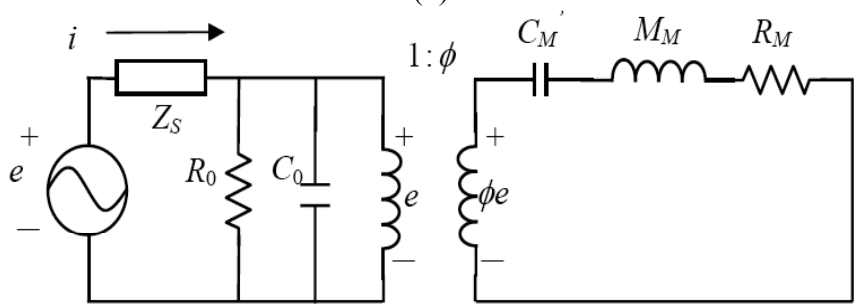

(b)

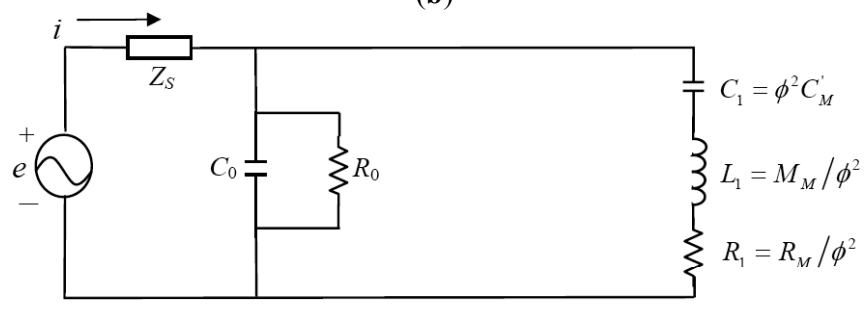

Fig. (3). Analogous circuit of the piezoelectric diaphragm. (a) The electrical and the mechanical circuits, (b) circuit expressed in the electrical domain.

\section{A. Electromechanical Two-Ports}

Before the FEM modeling, a brief review of two-port theory is given as follows. A transducer can be modeled by an electromechanical two-port, with two terminals in each port, as shown in Fig. (4). In the electrical port on the lefthand side, $e$ and $i$ denote voltage and current, respectively. In the mechanical port on the right-hand side, $\tilde{f}$ and $\bar{u}$ denote the total force and the averaged current, respectively. The two-port system can also be described by using the following linear matrix equation

$\left[\begin{array}{c}e \\ \tilde{f}\end{array}\right]=\left[\begin{array}{ll}Z_{e b} & T_{e m} \\ T_{m e} & Z_{m o}\end{array}\right]\left[\begin{array}{c}i \\ \bar{u}\end{array}\right]$

The impedance matrix

$\mathbf{Z}_{\text {piezo }}=\left[\begin{array}{ll}Z_{e b} & T_{e m} \\ T_{m e} & Z_{m o}\end{array}\right]$

contains four important parameters that govern the frequency-dependent characteristics of the two-ports. Specifically, $Z_{e b}=\left.\frac{e}{i}\right|_{u=0}$ represents blocked electrical impedance, $T_{e m}=\left.\frac{e}{\bar{u}}\right|_{i=0}=T_{m e}=\left.\frac{\tilde{f}}{i}\right|_{u=0} \quad$ represents electro-mechanical transduction coefficients (for reciprocal transducers such as piezoelectric transducers), and $Z_{m o}=\left.\frac{\tilde{f}}{\bar{u}}\right|_{i=0}$ represents opencircuit mechanical impedance.

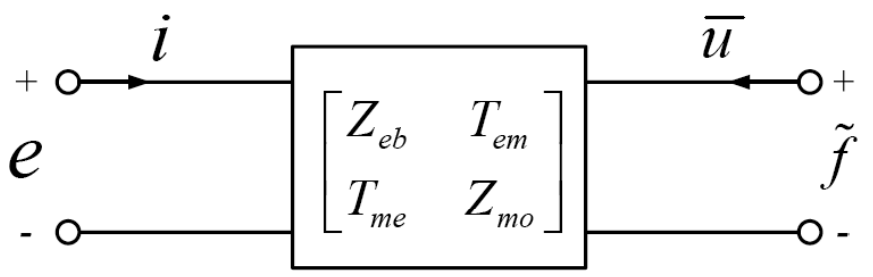

Fig. (4). Electromechanical two-ports model.

\section{B. Finite Element Analysis}

Finite element analysis is performed for the piezoelectric diaphragm (PZT and metal plate). The photos of a practical buzzer are shown in Fig. (5) for the following finite element analysis and the added-mass method to be addressed afterward. The dimensions of the piezoelectric buzzer are shown in Table 1. The material constants of the metal plate, clay, and PZT disc are shown in Table 2. The piezoelectric diaphragm is fitted in a plastic case. A pair of metal terminals are electrically connected to the piezoelectric diaphragm and drawn out from the rear cover of the plastic case (not shown in the photo). The finite element code used in this paper is ANSYS [19]. The finite element mesh for the piezoelectric diaphragm is depicted in Fig. (6). The metal plate is modeled by the SOLID 45 element, with eight nodes on each element and 3 degrees of freedom, including 3 displacements $\left(D_{x}, D_{y}\right.$, $D_{z}$ ) for each node. The PZT disc is modeled by the SOLID 5 
element, with eight nodes on each element and 4 degrees of freedom, including 3 displacements $\left(D_{x}, D_{y}, D_{z}\right)$ and one electric voltage $(\mathrm{V})$ for each node. The settings for the boundary conditions are selected to approximate the practical situation. The Z-displacement for the outer circle of the upper side of the metal plate is set to zero, as shown in Fig. (7a). The nodes at the circled nodes in Fig. (7b) on the lower side of the metal plate are pre-stressed for simulating the contact effect of the electric terminals. The amount of prestress is adjusted to match the first resonant frequencies of the calculated result obtained using FEM modal analysis and the measured data of the piezoelectric diaphragm. With several trials, $1.15 \mathrm{~N}$ is decided as the appropriate level of prestress. In addition, damping ratio $=0.0175$ is assumed.

(a)

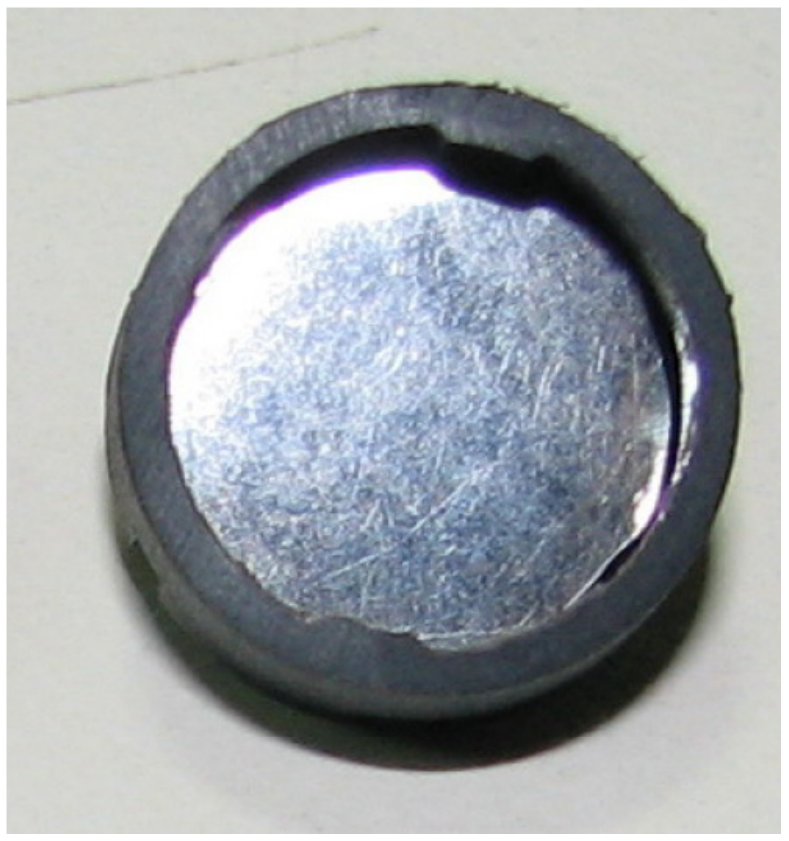

(b)

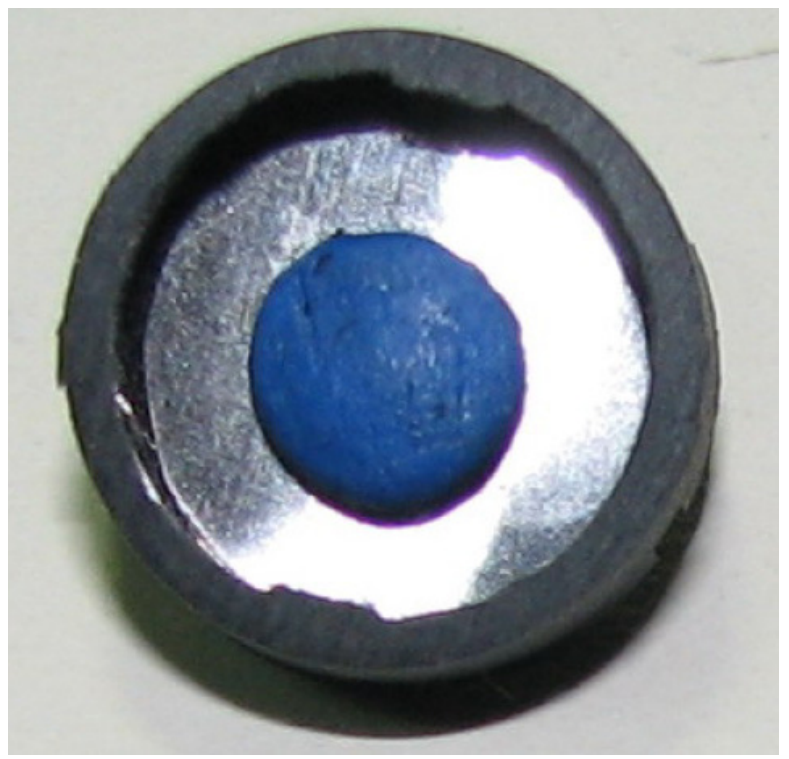

Fig. (5). Piezoelectric buzzer without the front cover. (a) Photo of the buzzer, (b) photo of the buzzer with the mass added on the diaphragm.

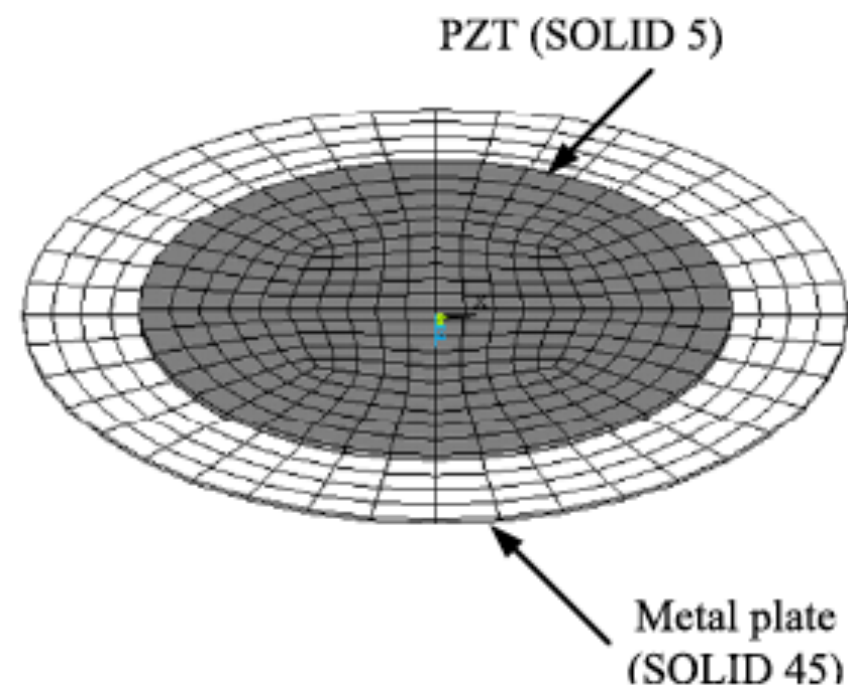

Fig. (6). The FEM mesh for the piezoelectric diaphragm.

The frequency response functions of $Z_{e b}, T_{e m}$ and $Z_{m o}$ in the aforementioned impedance matrix can be obtained from FEM harmonic analysis, as detailed in the following.

\section{a. Blocked Electrical Impedance, $Z_{e b}$}

Three displacements at every node are set to $0 \mathrm{~m}$. The amplitude of the sinusoidal voltage applied to the PZT is set to nominal $1 \mathrm{~V}$. The complex frequency response of the output current, calculated by varying the driving frequency of the sinusoidal input, is thus the frequency response of $Z_{e b}$.

\section{b. Open-Circuit Mechanical Impedance, $Z_{m o}$}

The current drawn from the piezoelectric diaphragm is set to 0A. The amplitude of the sinusoidal force applied to the $Z$ direction of every node of the PZT is set to nominal $1 \mathrm{~N}$. The calculated complex displacements are then averaged and converted to the averaged velocity, using the relation, $u=j \omega x, j=\sqrt{-1}, \omega:$ frequency, $x$ : displacement. The complex frequency response of the reciprocal of the averaged velocity, calculated by varying the driving frequency of the sinusoidal input, is thus the frequency response of $Z_{m o}$.

\section{c. Electro-Mechanical Transduction Coefficients, $T_{e m}=T_{m e}$}

Similar to the settings for obtaining $Z_{m o}$, the current drawn from the piezoelectric diaphragm is set to $0 \mathrm{~A}$, whereas the amplitude of the sinusoidal force applied to the $Z$ direction of every node of the PZT is set to nominal $1 \mathrm{~N}$. The complex frequency response of the ratio of the voltage output and the averaged velocity of the piezoelectric diaphragm, calculated by varying the driving frequency of the sinusoidal input, is thus the frequency response of $T_{e m}$.

\section{Modeling of The Acoustical System}

In the acoustical domain, the effects due to the cavity and port and radiation impedance will be modeled in the following. The cross section of the piezoelectric buzzer without front cavity is shown in Fig. (8a), with dimensions listed in 
Table 1. In Fig. (8a), $U_{D}$ is the volume velocity of the diaphragm, $Z_{A B}$ is the acoustical impedance of rear cavity, $Z_{A F}$ is the acoustical (radiation) impedance of the front cavity, and $V_{A B}$ is the volume of the rear cavity.

(a)

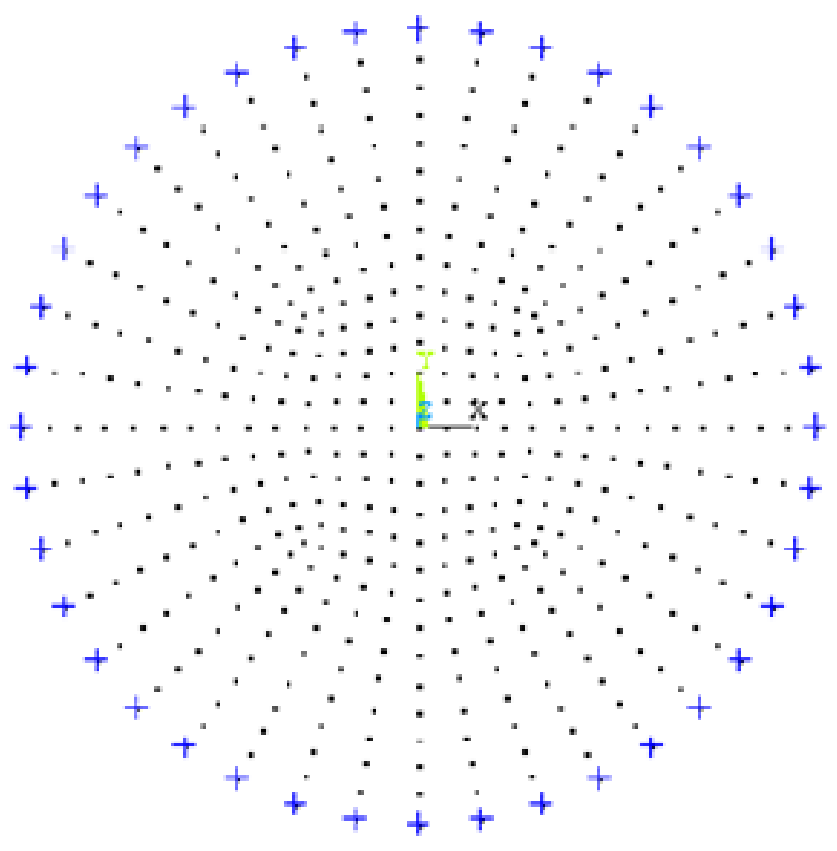

(b)

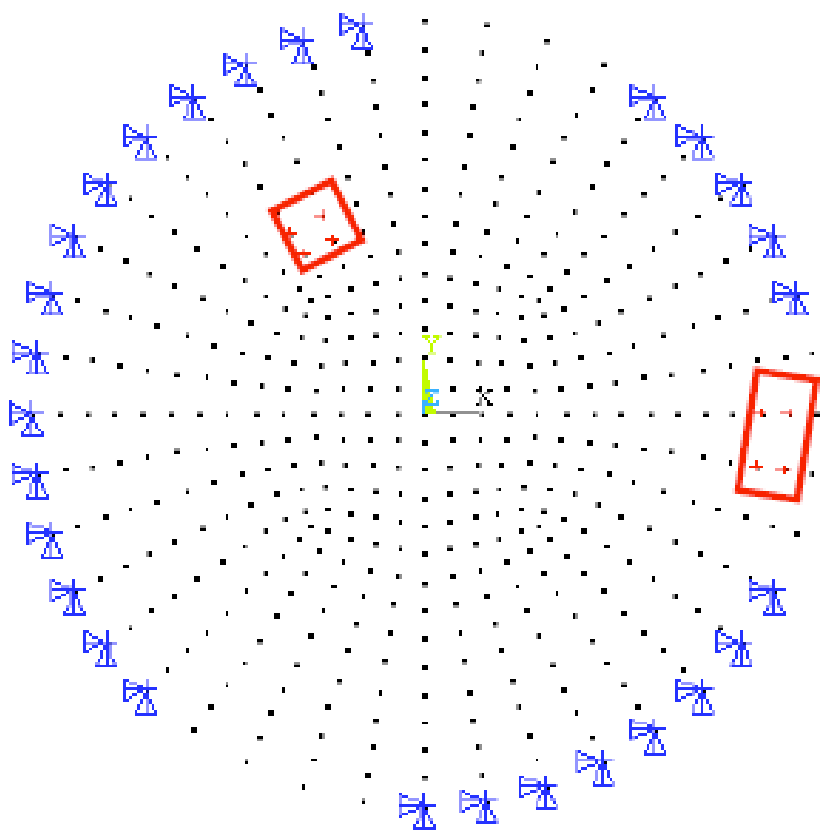

Fig. (7). The boundary conditions of the metal plate. (a) the upper layer, (b) the lower layer.

Fig. (8b) illustrates the overall acoustical impedance of the system in Fig. (8a), where $U_{D}$ is defined previously, $S_{D}$ is the area of diaphragm, $u_{D}$ is the averaged diaphragm velocity in the mechanical domain, $p_{B}$ is the pressure in the cavity, and $p_{F}$ is the pressure in the front of the diaphragm. Total acoustical impedance experienced by the diaphragm is

$Z_{A}=Z_{A F}+Z_{A B}$

In Fig. (8b), the parameters required for $Z_{A B}$ can be calculated using the following formulae:

$$
\begin{aligned}
& C_{A B}=\frac{V_{A B}}{\rho_{0} c^{2}} \\
& M_{A B}=\frac{B \rho_{0}}{\pi a_{A B}} \\
& B=\frac{d_{A B} \sqrt{\pi}}{3} \times \frac{S_{D}^{3 / 2}}{S_{B}^{2}}+\frac{8}{3 \pi}\left[1-\frac{S_{D}}{S_{B}}\right] \\
& R_{A B}=0,
\end{aligned}
$$

where $\rho_{0}$ is the density of air $\left(\rho_{0}=1.21 \mathrm{~kg} / \mathrm{m}^{3}\right), C_{A B}$ is the acoustic compliance of the rear cavity, $M_{A B}$ is the acoustic mass of the rear cavity, $R_{A B}$ is the acoustic resistance of the rear cavity, $B$ is the mass loading factor, $S_{B}$ is the area inside the back cavity, and $d_{A B}$ is the depth of the rear cavity.

On the other hand, the parameters required for $Z_{A F}$ can be calculated using the following formulas:

$$
\begin{aligned}
& C_{A F 1}=\frac{5.94 a_{A F}^{3}}{\rho_{0} c^{2}} \\
& M_{A F 1}=\frac{8 \rho_{0}}{3 \pi^{2} a_{A F}} \\
& R_{A F 1}=\left(\frac{128}{9 \pi^{2}}-1\right) \frac{\rho_{0} c}{\pi a_{A F}^{2}} \\
& R_{A F 2}=\frac{\rho_{0} c}{\pi a_{A F}^{2}},
\end{aligned}
$$

where $C_{A F 1}$ is the acoustic compliance for air load impedance, $M_{A F 1}$ is the acoustic mass for air load impedance, $R_{A F 1}$ and $R_{A F 2}$ are the acoustic resistors for air load impedance, and $a_{A F}$ is the radius of diaphragm.

\section{Frequency Response Simulation}

Fig. (9) shows a generic electro-mechanical two-ports of the piezoelectric buzzer without front cavity, with a Thevenin equivalent circuit (including a voltage source and a source impedance $Z_{S}$ ) and an acoustical load impedance $Z_{L}$ connected. Among them, $Z_{S}$ is the source impedance of Thevenin equivalent circuit. The driving-point impedance can be written as 
Table 2. The Material Constants of the Metal Plate, Clay, and PZT Disc

\begin{tabular}{|c|c|c|c|c|c|c|c|}
\hline Parameter & \multicolumn{2}{|l|}{ Metal Plate } & \multicolumn{3}{|c|}{ Clay } & & PZT \\
\hline Young's Modulus $\left(\mathrm{N} / \mathrm{m}^{2}\right)$ & $13.75 \mathrm{e} 10$ & \multicolumn{4}{|c|}{$9.28 \mathrm{e} 4$} & & \\
\hline Poisson ratio & 0.3 & \multicolumn{4}{|c|}{0.3} & & \\
\hline Density $\left(\mathrm{kg} / \mathrm{m}^{3}\right)$ & 8470 & & \multicolumn{3}{|c|}{9947.184} & & 7770 \\
\hline Piezoelectric constant $[e]$ & & {$\left[\begin{array}{c}0 \\
0 \\
0 \\
0 \\
10.2 \\
0\end{array}\right.$} & 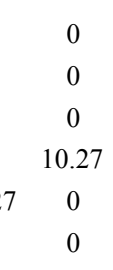 & $\left.\begin{array}{c}-14.13 \\
-14.13 \\
14.7 \\
0 \\
0 \\
0\end{array}\right]$ & & & \\
\hline Elastic stiffness $[c]$ & {$[9.97 e 10$} & $\begin{array}{r}5.26 e 10 \\
9.97 e 10 \\
\text { symmetric }\end{array}$ & $\begin{array}{c}4.80 e 10 \\
4.80 e 10 \\
10.44 e 10\end{array}$ & $\begin{array}{c}0 \\
0 \\
0 \\
2.36 e 10\end{array}$ & $\begin{array}{c}0 \\
0 \\
0 \\
0 \\
2.9 e 10\end{array}$ & $\left.\begin{array}{c}0 \\
0 \\
0 \\
0 \\
0 \\
2.9 e 10\end{array}\right]$ & \\
\hline Permittivity at constant strain $\left[\varepsilon^{s}\right]$ & & {$\left[\begin{array}{c}8.6 e-9 \\
0 \\
0\end{array}\right.$} & $\begin{array}{c}0 \\
8.6 e-9 \\
0\end{array}$ & $\begin{array}{c}0 \\
0 \\
6.624 e-\end{array}$ & & & \\
\hline
\end{tabular}

(a)

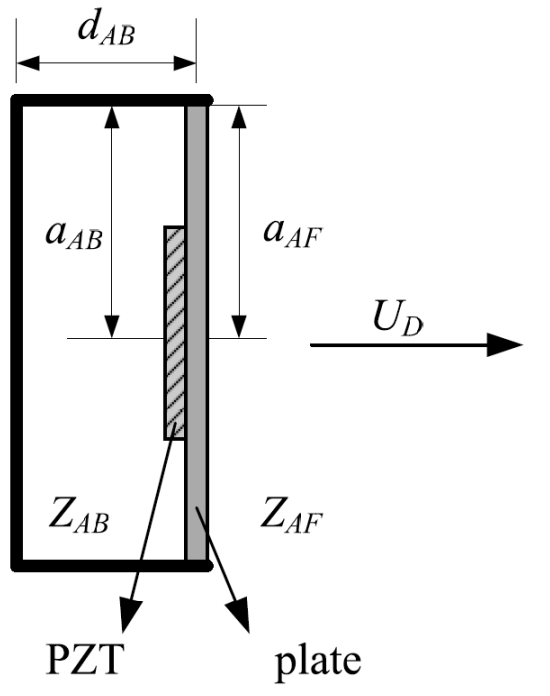

(b)

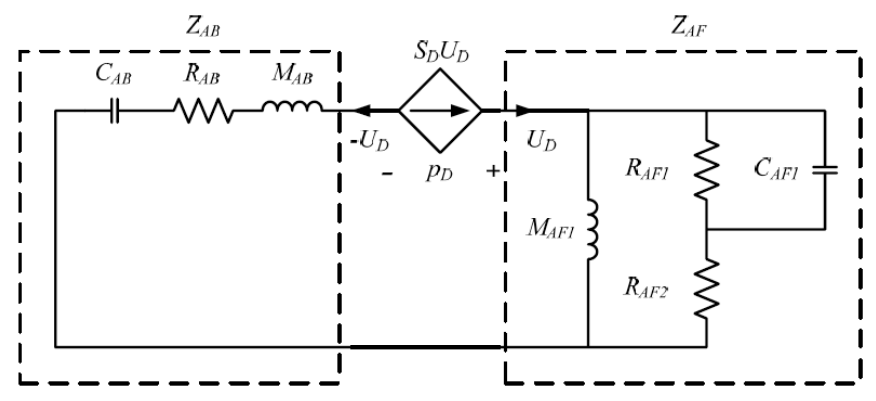

Fig. (8). The cross section of the piezoelectric buzzer without the front cavity. (a) Photo of the cross section, (b) the analogous circuits of acoustical load impedance.

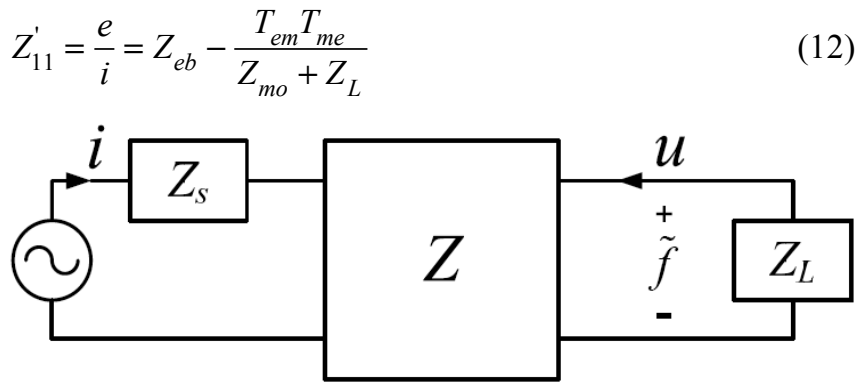

Fig. (9). The analogous circuit of the piezoelectric buzzer without the front cavity, expressed in the electrical system, the electromechanical two-ports, and the acoustical load impedance.

In order to facilitate the formulation of lumped parameter circuit of the piezoelectric diaphragm, an added-mass technique similar to that used in moving-coil loudspeaker is devised. This technique starts with the calculation of electrical impedance curves of the piezoelectric diaphragm using Eq. (12), with and without a $0.05 \mathrm{~g}$ mass. The mass added must be sufficiently large to shift the electrical impedance for notably different pole and zero. The parameter identification procedure can be summarized as follows. Locate the serial resonant frequency $\left(f_{s}\right)$, parallel resonant frequency $\left(f_{p}\right)$ and structural resonant frequency $\left(f_{m}\right)$ from the impedance curve without mass. The analogous circuit of the piezoelectric diaphragm is shown in Fig. (3a,b). Estimate the static capacitance $\left(C_{0}\right)$, dynamic capacitance $\left(C_{1}\right)$, inductance $\left(L_{1}\right)$ and quality factor $(Q)$ from the serial resonant frequency $\left(f_{s}\right)$ and the parallel resonant frequency $\left(f_{p}\right)$. With a conversion procedure, the transduction factor $(\phi)$, the me- 
chanical resistance $\left(R_{M}\right)$, the mechanical compliance $\left(C_{M}\right)$ and the mechanical mass $\left(M_{M}\right)$ from the resonant frequencies of the piezoelectric diaphragm without and with the mass, respectively, can be calculated. The details of the forgoing procedure can be found in Ref. [20]. Using the procedure, the lumped parameters of the piezoelectric diaphragm were calculated and summarized in Table $\mathbf{3}$. The errors between the calculated and the measured parameters are mostly within $5 \%$. Notable exception is the error in estimating the mechanical resistance $\left(R_{m}\right)$ or the damping which can be difficult to characterize in practice. The squared ratio of the serial resonant frequency $\left(f_{s}\right)$ to the parallel resonant frequency $\left(f_{p}\right)$ affects the estimation of the static and dynamic capacitance $\left(C_{0}\right.$ and $\left.C_{1}\right)$.

Table 3. Lumped Parameters of the FEM-Based Piezoelectric Diaphragm

\begin{tabular}{|c|c|c|c|}
\hline Parameter & Experiment & ANSYS & Error (\%) \\
\hline \hline$f_{\mathrm{p}}(\mathrm{Hz})$ & 4812.5 & 4870 & 1.2 \\
\hline$f_{\mathrm{s}}(\mathrm{Hz})$ & 4743.8 & 4757.5 & 0.3 \\
\hline$C_{0}(\mathrm{~F})$ & $7.43 \mathrm{E}-9$ & $8.75 \mathrm{E}-9$ & 17.8 \\
\hline$C_{1}(\mathrm{~F})$ & $2.17 \mathrm{E}-10$ & $4.19 \mathrm{E}-10$ & 93.2 \\
\hline$L_{1}(\mathrm{~F})$ & 5.1907 & 2.6733 & -48.5 \\
\hline$R_{1}(\mathrm{ohm})$ & 6616.8 & 2757.1 & -58.3 \\
\hline$R_{0}(\mathrm{ohm})$ & $9.49 \mathrm{E} 6$ & $1.02 \mathrm{E} 7$ & 7.5 \\
\hline$f_{\mathrm{m}}(\mathrm{Hz})$ & 4656.3 & 4667.5 & 0.2 \\
\hline$f_{\mathrm{m}}$ with $\mathrm{mass}(\mathrm{Hz})$ & 3368.8 & 3407.5 & 1.1 \\
\hline$M_{M}(\mathrm{~kg})$ & $5.49 \mathrm{E}-5$ & $5.71 \mathrm{E}-5$ & 4 \\
\hline$C_{M}^{\prime}(\mathrm{m} / \mathrm{N})$ & $2.13 \mathrm{E}-5$ & $2.04 \mathrm{E}-5$ & -4.1 \\
\hline$R_{M}(\mathrm{Ns} / \mathrm{m})$ & 0.054633 & 0.0204 & -62.7 \\
\hline$\phi(\mathrm{N} / \mathrm{V})$ & 0.002873 & 0.00272 & -5.3 \\
\hline
\end{tabular}

With the identified lumped parameters of the piezoelectric diaphragm, the response of the buzzer can be simulated using the EMA analogous circuit in Fig. (10). In the acoustical domain, the acoustical mass of the port $\left(M_{A P}\right)$, the acoustical resistance of the port $\left(R_{A P}\right)$, and the acoustical compliance of the front cavity $\left(C_{A F}\right)$ are calculated using the following formulas [14]:

$$
\begin{aligned}
& M_{A P}=\frac{\rho_{0}}{\pi a_{p}^{2}}\left(t_{c}+1.462 a_{p}\right) \\
& R_{A P}=\frac{\rho_{0}}{\pi a_{p}^{2}} \sqrt{2 \omega \mu}\left[\frac{t_{c}}{a_{p}}+6.4\left(1-\frac{\pi a_{p}^{2}}{b^{2}}\right)\right] \\
& C_{A F}=\frac{V_{A F}}{\rho_{0} c^{2}},
\end{aligned}
$$

where $a_{p}$ is the radius of port, $t_{c}$ is the thickness of the front cavity, $\mu$ is the viscosity coefficient ( $\left.\mu=1.56 \times 10^{-5} \mathrm{~m}^{2} / \mathrm{s}\right), b$ is the diameter of the piezoelectric diaphragm, $V_{A F}$ is the volume of the front cavity, $c$ is the speed of sound ( $c \approx 345 \mathrm{~m} / \mathrm{s}$ at the room temperature), and $\rho_{0}$ is the density of air $\left(\rho_{0}=1.21 \mathrm{~kg} / \mathrm{m}^{3}\right)$. It can be shown that the loop equations [16] corresponding to the analogous circuit of Fig. (10) can be written as the following matrix equation:

$$
\left[\begin{array}{ccccc}
Z_{S}+Z_{E B} & -\phi Z_{E B} & 0 & 0 & 0 \\
Z_{E B} & -\phi Z_{E B} & -1 & 0 & 0 \\
0 & Z_{m s} & -\phi & S_{d} & 0 \\
0 & -S_{d}\left(M_{A P} s+\frac{1}{C_{A F} s}\right) & 1 & 0 & \frac{1}{C_{A F} s} \\
0 & \frac{-S_{d}}{C_{A F} s} & 0 & 0 & M_{A P} s+\frac{1}{C_{A F} s}+R_{A P}
\end{array}\right]\left[\begin{array}{c}
i \\
u \\
e \\
e^{\prime} \\
i^{\prime}
\end{array}\right]=\left[\begin{array}{c}
e_{g} \\
0 \\
0 \\
0 \\
0
\end{array}\right],
$$

where $e_{g}$ is the driving voltage, $s=j \omega$ is the Laplace variable, and

$$
\begin{aligned}
& Z_{E B}=\frac{1}{C_{0} s} \| R_{0} \\
& Z_{m s}=Z_{M} \approx M_{M} s+\frac{1}{C_{M}^{\prime} s}+R_{M}
\end{aligned}
$$

Electrical impedance and the sound pressure output of the buzzer can be simulated by solving the loop equations for the electrical and mechanical unknowns. The modeling procedures above can be summarized as follows:

a. Perform FEM modal analysis and harmonic analysis. Tune FEM parameters using the modal analysis.

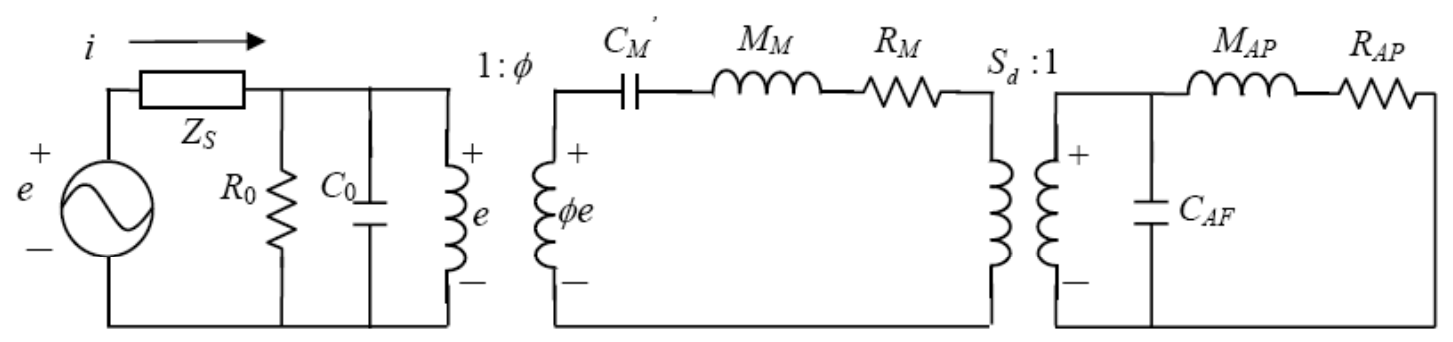

Fig. (10). The EMA analogous circuit of the piezoelectric buzzer. 
b. Calculate the frequency response functions of the two-port parameters based on the FEM harmonic analysis above.

c. Convert the FEM-based two-port model into the lumped parameter model using the added mass method.

d. Solve loop equations of the analogous circuits to simulate the dynamic response.

\section{E. Theory of Dynamic Vibration Absorber}

The design of a resonant acoustical device, here a piezoelectric buzzer, shares quite similar electroacoustical chacteristics with the preceding vibration absorber problem. Fig. (11) shows the structure in the mechanical domain, where a serial second-order oscillator circuit is coupled with a parallel second-order oscillator circuit. It is mathematically easier to derive the system characteristic equation by having a parallel resistance $R A L$ on the mechanical side, with $R A P$ neglected, in the circuit. Nevertheless, in deriving the design chart, only the undamped resonant frequencies are of concern. The actual position of the mechanical resistor is immaterial since both resistors are removed in the circuit of the coupled system. Note, however, that the port loss RAP is considered in the constrained optimization procedures with the circuit of Fig. (3). When $\omega_{A}=\omega_{M}$, the motion of the mechanical system cancels that of the acoustical system, or alternatively viewed, the infinitely large impedance of the acoustical system "blocks" the motion of the mechanical system. This is the feature that is frequently exploited to suppress vibrations, which forms the basis of vibration absorber theory. However, in the case of resonant acoustical devices, the naive approach of choosing equal resonant frequencies for both systems will result in an unexpected response null at $\omega_{A}=\omega_{M}$. This is obviously undesirable in the buzzer design. Contrary to vibration control, where one seeks to minimize the response, our purpose here in the acoustical design of buzzer is to maximize the sound pressure output, and it is the peaks of frequency response that we are after.

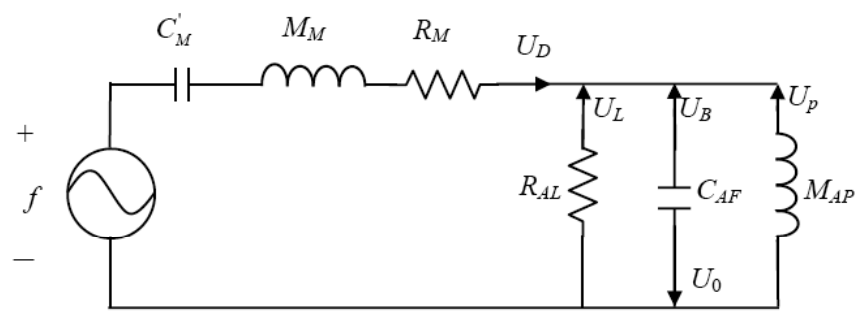

Fig. (11). A simplified analogous circuit of the piezoelectric buzzer expressed in the mechanical domain.

Let $U_{0}$ be the total velocity emitted from the diaphragm, the port, and the air leaks. From Fig. (11),

$U_{0}=U_{D}+U_{P}+U_{L}=-U_{B}$,

where $U_{B}$ is the net velocity entering the enclosure. The mechanical impedance and the acoustical impedance are given by

$$
\begin{gathered}
Z_{M}=M_{M} s+R_{M}+\frac{1}{C_{M}^{\prime} s}=\frac{\frac{s^{2}}{\omega_{M}^{2}}+\frac{1}{Q_{M}} \frac{s}{\omega_{M}}+1}{C_{M}^{\prime} s} \\
Y_{A}=C_{A F} s+\frac{1}{R_{A L}}+\frac{1}{M_{A P} s}=\frac{\frac{s^{2}}{\omega_{A}^{2}}+\frac{1}{Q_{A}} \frac{s}{\omega_{A}}+1}{M_{A P} s}
\end{gathered}
$$

The total electrical impedance can be written as the sum of the mechanical impedance and the acoustical impedance:

$$
Z_{T}=Z_{M}+\frac{1}{Y_{A}}=\frac{\Delta(s)}{C_{M}^{\prime} s\left(\frac{s^{2}}{\omega_{A}{ }^{2}}+\frac{1}{Q_{A}} \frac{s}{\omega_{A}}+1\right)},
$$

where

$$
\Delta(s)=\left(\frac{s^{2}}{\omega_{M}^{2}}+\frac{1}{Q_{M}} \frac{s}{\omega_{M}}+1\right)\left(\frac{s^{2}}{\omega_{A}^{2}}+\frac{1}{Q_{A}} \frac{s}{\omega_{A}}+1\right)+M_{A P} C_{M}^{\prime} s^{2},
$$

denotes the characteristic equation, $\omega_{M}$ is the resonant frequency of the mechanical system (the piezoelectric diaphragm)

$\omega_{M}=\sqrt{\frac{1}{M_{M} C_{M}^{\prime}}}$,

$\omega_{A}$ is the resonant frequency of the acoustical system (the cavity and port),

$\omega_{A}=\sqrt{\frac{1}{M_{A P} C_{A F}}}$,

$Q_{M}$ and $Q_{A}$ are the quality factors of the mechanical system and the acoustical system, respectively, given by

$$
\begin{aligned}
& Q_{M}=\frac{1}{R_{M} C_{M}^{\prime} \omega_{M}} \\
& Q_{A}=\frac{R_{A L}}{C_{A F} \omega_{A}}
\end{aligned}
$$

It can be shown that the characteristic equation in Eq. (23) can be rewritten into an alternative form

$$
\Delta=\frac{s^{4}}{\omega_{0}^{4}}+a_{3} \frac{s^{3}}{\omega_{0}^{3}}+a_{2} \frac{s^{2}}{\omega_{0}^{2}}+a_{1} \frac{s}{\omega_{0}}+1=0,
$$

where the frequency $\omega_{0}$ and the coefficients $a_{1}, a_{2}$, and $a_{3}$ are defined as

$$
\begin{aligned}
& \omega_{0}=\sqrt{\omega_{A} \omega_{M}}=\frac{\omega_{M}}{\sqrt{\alpha}}=\omega_{A} \sqrt{\alpha} \\
& a_{1}=\frac{1}{Q_{M} \sqrt{\alpha}}+\frac{\sqrt{\alpha}}{Q_{A}}
\end{aligned}
$$


$a_{2}=\frac{1}{\alpha}+\alpha+\frac{1}{Q_{M} Q_{A}}+\frac{\rho}{\alpha}$

$a_{3}=\frac{1}{Q_{A} \sqrt{\alpha}}+\frac{\sqrt{\alpha}}{Q_{M}}$

In these equations, the frequency ratio $\alpha$ and the mass ratio $\rho$ are defined as

$\alpha=\frac{\omega_{M}}{\omega_{A}}>0$

$\rho=\frac{M_{A P}}{M_{M}}>0$

For undamped systems, where $Q_{M} \rightarrow \infty$ and $Q_{A} \rightarrow \infty$, the characteristic equation simplifies to

$\Delta(s)=\alpha^{2} r_{M}^{4}-\left(1+\alpha^{2}+\rho\right) r_{M}^{2}+1=0$

in which the normalized frequency $r_{M}$ is defined as

$r_{M}=\frac{\omega}{\omega_{M}}$

Solving for the roots of the characteristic equation yields two undamped natural (resonance) frequencies. Note that the resonance frequencies of the coupled (mechanical and acoustical) system are generally different from, but strongly influenced by, those of the individual subsystems. According to Eq. (35), the resonance frequencies of the coupled system can be plotted versus the mass ratio $\rho$ for various frequency ratios $\alpha$. This gives the design charts shown in Fig. (12a,b), in which the curves for mass ratio $\rho>0$ are in used, while the curves for mass ratio $\rho \leq 0$ are only mathematical.

Assuming that the properties of the mechanical system are fixed, we now focus on the design of the acoustical system with the aid of the design chart. The design variables we wish to determine are the volume of cavity, the radius of port, and the length of duct. The design procedure is outlined as follows:

1. Specify design constraints. Fix the mechanical resonant frequency $\left(f_{M}=\omega_{M} / 2 \pi\right)$ of the piezoelectric diaphragm. Assume $f_{A}=\omega_{A} / 2 \pi<f_{M}$.

2. Fix the first resonant frequency $\left(f_{1}=\omega_{1} / 2 \pi\right)$ of the coupled system (piezoelectric buzzer) at the driving frequency, e.g., $4 \mathrm{kHz}$.

3. From the mechanical resonant frequency $\left(f_{M}\right)$ and the first resonant frequency $\left(f_{1}\right)$, calculate the normalized frequency $\left(r_{1}=f_{1} / f_{M}\right)$.

4. Choose a mass ratio $(\rho)$ and determine the acoustical $\operatorname{mass}\left(M_{A P}\right)$.
5. Assume a value for the radius of port $\left(a_{p}\right)$. Determine the length of duct ( $\left.t_{c}\right)$ according to Eq. (13).

6. Choose the design curve ( $\alpha$ ) that corresponds to the normalize frequency and mass ratio determined previously.

7. Determine the acoustical resonant frequency, $f_{A}=f_{M} / \alpha$.

8. Per Eq. (25), calculate the acoustical compliance $\left(C_{A}\right)$ based on $M_{A P}$ and $f_{M}$. Also calculate the cavity volume according to Eq. (15).

(a)

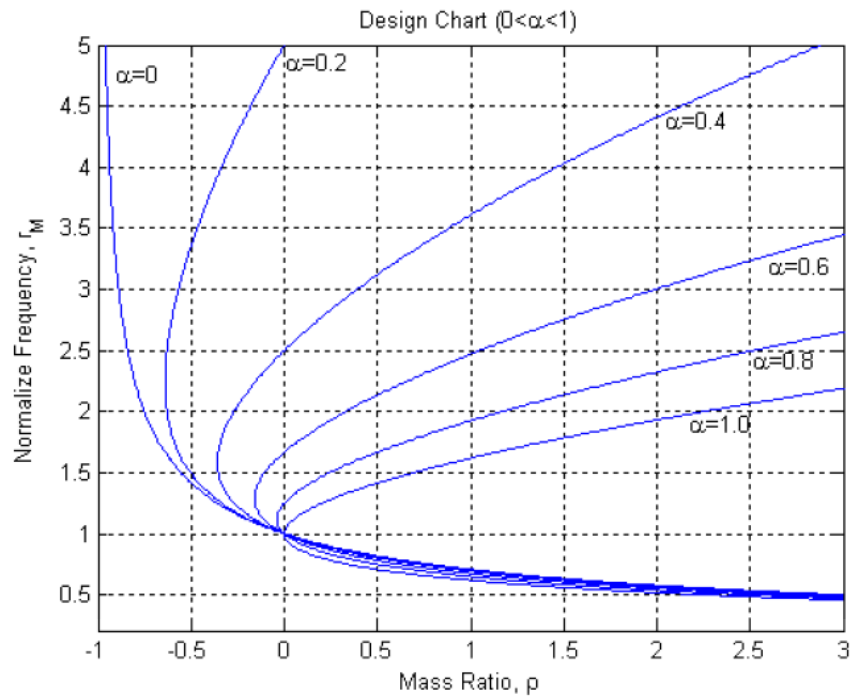

(b)

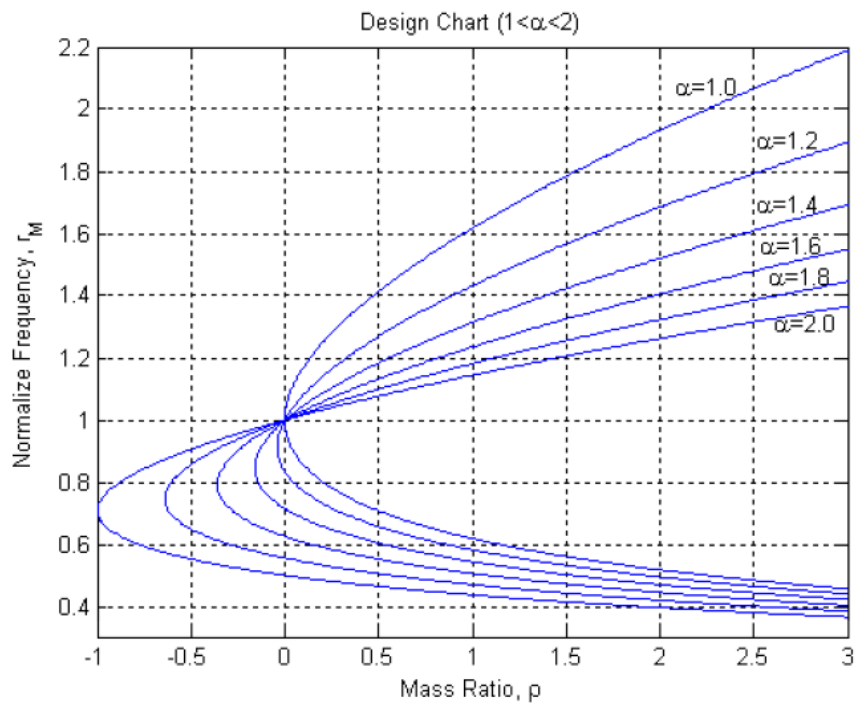

Fig. (12). The design chart of the piezoelectric buzzer. (a) $0 \leq \alpha \leq 1$, (b) $1 \leq \alpha \leq 2$.

\section{OPTIMAL DESIGN OF THE PIEZOELECTRIC BUZZER}

In this section, optimization design using Taguchi method and sensitivity analysis will be presented. The purpose here is to find the optimal parameters of the piezoelec- 
tric diaphragm that maximizes the sound pressure output at the driving frequency.

\section{A. Taguchi Method}

Taguchi method [18] is an experimental design procedure well suited for multi- factor design problems using a minimum number of observations. A general Taguchi procedure provides three kinds of functions: system design, parameter design and tolerance design. For our optimal problem at hand, we focus on the interactions of physical parameter. To illustrate how the Taguchi procedure is applied to the buzzer design, we start with a $L_{9}\left(3^{4}\right)$ orthogonal array shown in Table 4. The notation $L_{9}\left(3^{4}\right)$ means that the experimental design requires nine observations and four factors. All factors are in three levels. The parameters considered in the design are the radius of the PZT plate, the density of the PZT plate, the Young's modulus of the metal plate, and $d_{31}$, as designated as Factors 1-4 in Table 4. In Factors 1-3, the levels of parameters are arranged in ascending order, while in Factor 4 the levels of parameters are arranged in descending order. However, in Table 2 , the change of $d_{31}$ will influence the value of elastic stiffness and permittivity at constant strain. The values of $e_{31}, e_{33}$ and $\varepsilon_{33}$ [20] will be changed according to the following relation:

$$
\begin{aligned}
& e_{31}=d_{31}\left(c_{11}^{E}+c_{12}^{E}\right)+d_{33} c_{13}^{E} \\
& e_{33}=2 d_{31} c_{13}^{E}+d_{33} c_{33}^{E} \\
& \varepsilon_{33}^{S}=\varepsilon_{33}^{T}-2 d_{31} e_{31}-d_{33} e_{33}
\end{aligned}
$$

The converted values are listed in Table 4 . The parameter combination that attains maximal sound pressure response according to the $L_{9}\left(3^{4}\right)$ orthogonal array serves as the initial setting for the following design optimization.

\section{B. Design Optimization}

The optimization procedure is based on two approaches, the design chart and the constrained optimization, in light of a vibration absorber theory [14]. It is assumed that the mechanical properties are fixed. Design is focused on the acoustical system, with the aid of the design chart. The design variables we wish to optimize are the volume of cavity, the radius of port, and the length of duct. The constrained opti-

\begin{tabular}{|c|c|c|c|c|}
\hline Run & $\mathbf{A}$ & B & C & D \\
\hline 2 & 1 & 2 & 2 & 2 \\
\hline 5 & 2 & 2 & 3 & 1 \\
\hline 6 & 2 & 3 & 1 & 2 \\
\hline 7 & 3 & 1 & 3 & 2 \\
\hline \multicolumn{2}{|c|}{ Factor } & Level1 & Level2 & Level3 \\
\hline \multicolumn{2}{|c|}{ A. Radius of PZT (mm) } & 3.6 & 4 & 4.4 \\
\hline \multicolumn{2}{|c|}{ B. Density $\left(\mathrm{Kg} / \mathrm{m}^{3}\right)$} & 7200 & 7770 & 8200 \\
\hline \multicolumn{2}{|c|}{ C. Young's modulus $\left(\mathrm{N} / \mathrm{m}^{2}\right)$} & $10.3 \mathrm{e} 10$ & $13.75 \mathrm{e} 10$ & $16 \mathrm{e} 10$ \\
\hline \multirow{2}{*}{\multicolumn{2}{|c|}{ D. Value of $d_{31}$}} & $d_{31}=-1.5469 e-10$ & $d_{31}=-1.93357 e-10$ & $d_{31}=-2.417 e-10$ \\
\hline & & $e_{31}=-8.2406$ & $e_{31}=-14.1296$ & $e_{31}=-21.4907$ \\
\hline
\end{tabular}
mization approach also focuses on the acoustical system

Table 4. The $L_{9}\left(3^{4}\right)$ Orthogonal Array of Taguchi Method 
only. The volume of cavity, the port size, and the duct length are to be determined, where the best parameters of the mechanical system found in orthogonal array of the preceding Taguchi procedure will be assumed. Optimization is carried out by using the Matlab [21]. Design factors including acoustical mass $\left(M_{A P}\right)$, acoustical compliance $\left(C_{A F}\right)$, acoustical resistance $\left(R_{A P}\right)$, the $1^{\text {st }}$ resonant frequency of piezoelectric buzzer $\left(f_{1}=4 \mathrm{kHz}\right)$, characteristic equation of piezoelectric buzzer (characteristic equation $\Delta(s)=0$ ), radius of port $\left(a_{p}\right)$, length of duct $\left(t_{c}\right)$ and height of front cavity $\left(d_{A F}\right)$, are constrained within practical limits. Among them, $a_{p}, t_{c}$ and $d_{A F}$ are also selected to the design variables for optimization. The optimization formalism can be stated as maximizing the sound pressure level (SPL) at the driving frequency under the prescribed engineering constraints, i.e.,

$$
\begin{aligned}
& \max \operatorname{SPL}\left(a_{p}, t_{c}, d_{A F}\right) \\
& \text { st. }\left\{\begin{array}{c}
0.0005 \leq a_{p} \leq 0.002 \\
0.0005 \leq t_{c} \leq 0.005 \\
0.0025 \leq d_{A F} \leq 0.005 \\
1 e^{-7} \leq M_{A P} \leq 1 e^{-5} \\
2 e^{5} \leq R_{A P} \leq 2 e^{7} \\
1 e^{-4} \leq C_{A F} \leq 3 e^{-4} \\
f_{1}=4000 \\
\Delta=0
\end{array}\right.
\end{aligned}
$$

\section{Sensitivity Analysis}

To facilitate the tuning of physical parameters in the buzzer design, a sensitivity analysis can be conducted to examine the effect of physical parameters of the piezoelectric diaphragm on the lumped parameters. The parameters considered in the sensitivity analysis are the same as the factor design in the $L_{9}\left(3^{4}\right)$ orthogonal array.

\section{NUMERICAL AND EXPERIMENTAL INVESTI- GATIONS}

Simulation and experimental investigations are undertaken for validating the aforementioned design technique. The piezoelectric buzzer is embedded in a baffle. The experimental arrangement in an anechoic room is shown in Fig. (13). A 1.5 Vrms swept sine signal is generated to drive the piezoelectric buzzer, with the frequency ranging from $1 \mathrm{kHz}$ to $10 \mathrm{kHz}$. On-axis sound pressure response was measured by a microphone positioned at $10 \mathrm{~cm}$ away from the piezoelectric buzzer.

\section{A. Response Simulation and Experimental Investigation}

Simulation of the piezoelectric diaphragm response was carried out on the basis of the finite element model. FEM modal analysis shows that the first three natural frequencies

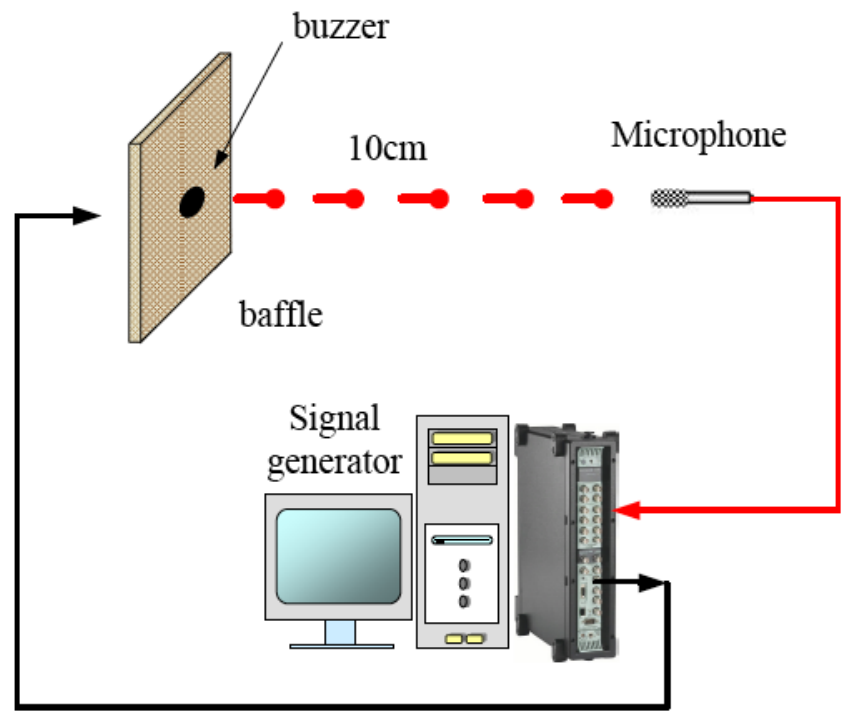

Fig. (13). Experimental arrangement of the piezoelectric buzzer.

of the piezoelectric diaphragm obtained by modal analysis are $4952 \mathrm{~Hz}, 9054 \mathrm{~Hz}$ and $10238 \mathrm{~Hz}$, respectively. The mode shape of the first mode is shown in Fig. (14). The first resonant frequency $4952 \mathrm{~Hz}$ allows for the determination of prestress $(1.15 \mathrm{~N})$. Using FEM harmonic analysis, and the frequency response for the two-port parameters,

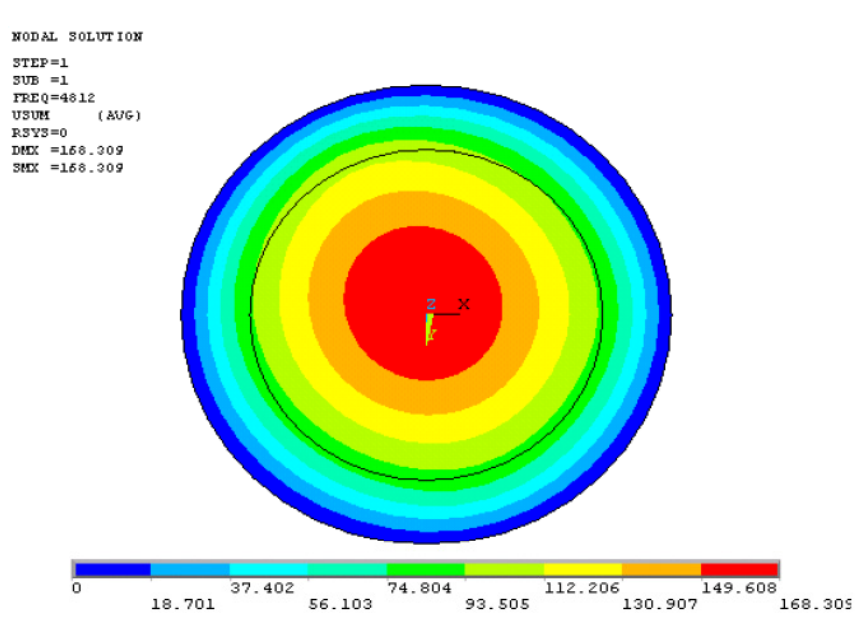

Fig. (14). The first mode shape of the piezoelectric diaphragm.

$\left(Z_{e b}, T_{e m}=T_{m e}, Z_{m o}\right)$, is shown in Fig. (15a-c). The solid line represents the impedance measured without the mass. The dashed line represents the impedance measured with the $0.05 \mathrm{~g}$ mass. Based on the two-port parameters, the electrical impedance can be simulated using Eq. (12). Fig. (16) shows the electrical impedance obtained from the simulation and experiment. The simulated electrical impedance is in reasonable agreement with that of the measured results. The resonant frequency has been decreased from $4667.5 \mathrm{~Hz}$ to 3407.5 $\mathrm{Hz}$ apparently because of the added $0.05 \mathrm{~g}$ mass. Lumped parameters can then be estimated using these two impedance curves. Next, the electrical impedance and on-axis sound pressure response of the entire piezoelectric buzzer can be simulated by solving the loop equations of the EMA analogous circuit. Fig. (17a,b) show the electrical impedance and 
(a)

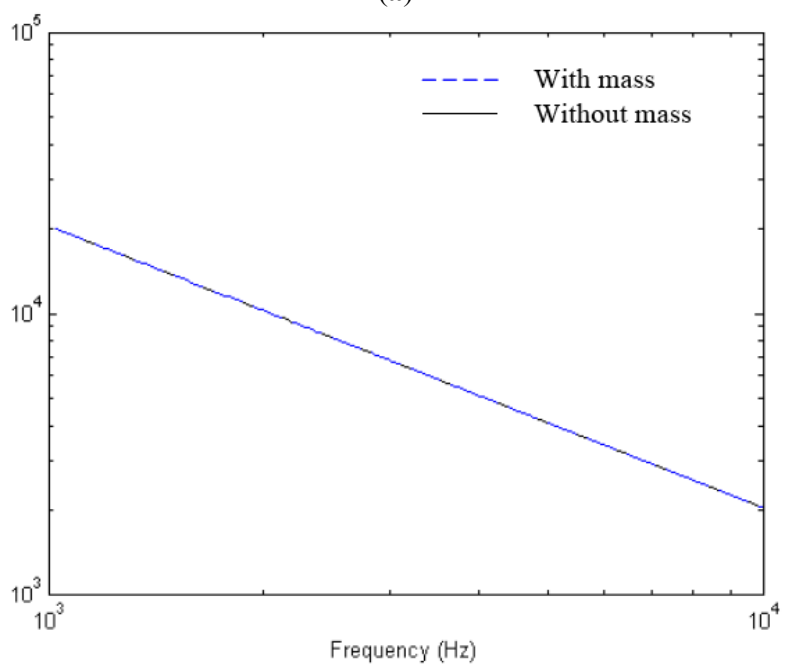

(b)

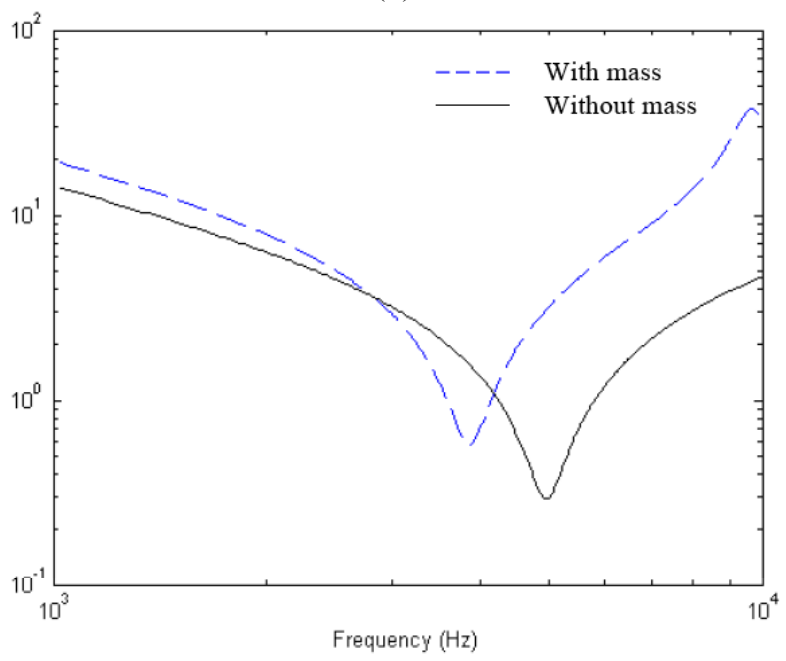

(c)

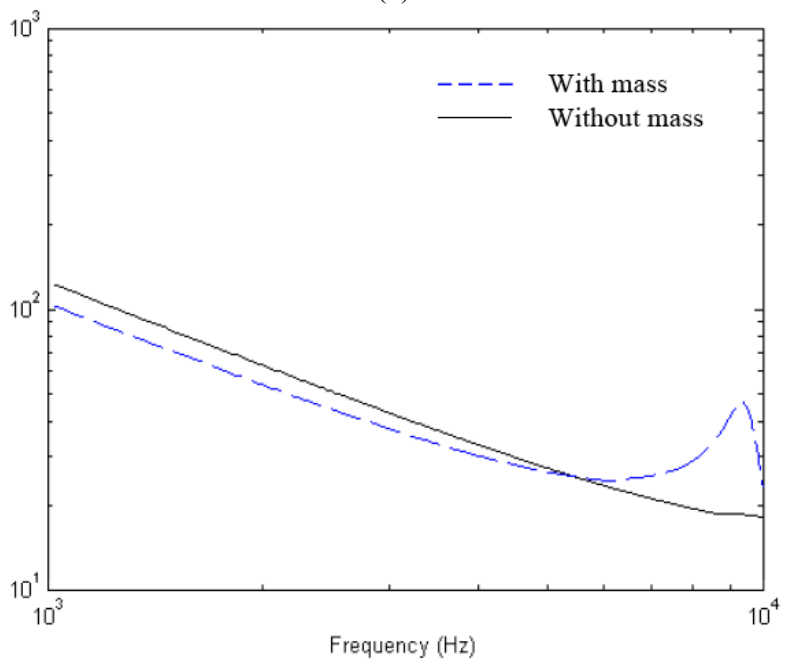

Fig. (15). The frequency response functions of the two-port parameters obtained using FEM harmonic analysis. (a) Frequency response of the blocked electrical impedance $\left(Z_{e b}\right)$, (b) frequency response of the electro-mechanical transduction coefficients $\left(T_{e m}\right.$ or $\left.T_{m e}\right)$, (c) frequency response of the open-circuit mechanical impedance $\left(Z_{m o}\right)$.

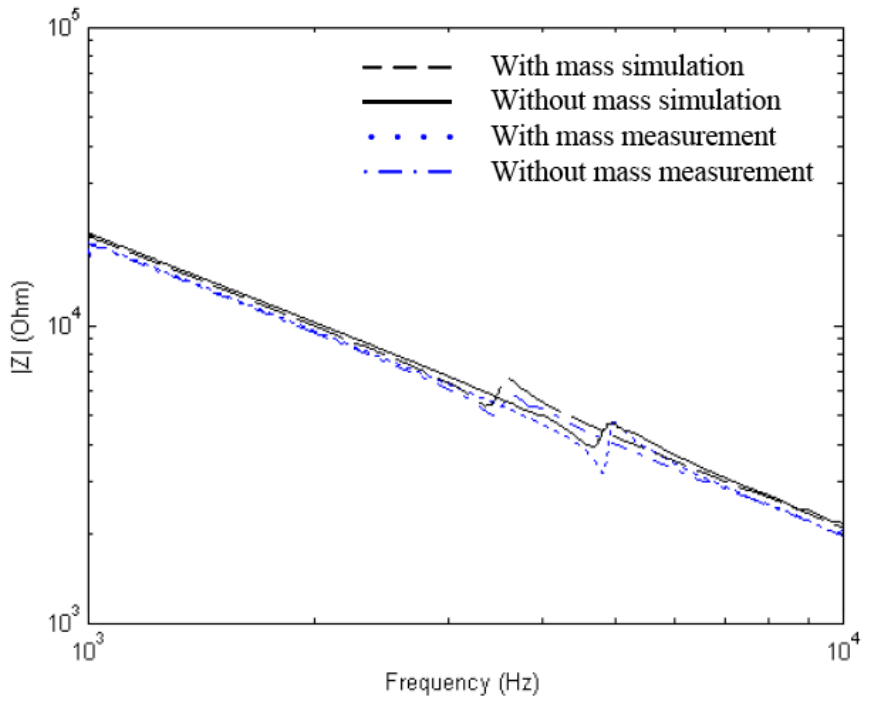

Fig. (16). The electrical impedance of the piezoelectric diaphragm obtained from the simulation and experiment.

the on-axis SPL obtained from the simulation and experiment, respectively. It can be observed that the simulated responses are in reasonable agreement with those of the measured results. Except for some minor discrepancies due to damping ratio and pre-stress, the main features such as the main peaks are well captured by the lumped parameter model.

\section{B. Results of Taguchi and Sensitivity Analysis}

A preliminary search for acceptable design is conducted using Taguchi method with the interactions of physical parameters taken into account. The results of Run 1 to Run 9 of the $L_{9}\left(3^{4}\right)$ orthogonal array are summarized in Table $\mathbf{5}$, where the SPL is calculated for the first mode of piezoelectric diaphragm. Various degrees of influence of physical parameters on the resulting SPL can be observed with the order: radius of the PZT diaphragm, $d_{31}$ of the PZT diaphragm, Young's modulus of the metal plate, and the density of the PZT diaphragm. Using the preceding simulation model with the parameters in Table 5, the on-axis SPLs of the piezoelectric buzzer can be simulated, as shown in Fig. $(\mathbf{1 8 a}, \mathbf{b})$. The SPL of Run 7 is particularly high among all cases. Using this Taguchi result of Run 7 as the initial design, optimization is carried out. The optimized results are shown in Table 6 and Fig. (19). In Fig. (19), the on-axis SPL of the constrained optimization is greater than the design chart at the driving frequency $4 \mathrm{kHz}$, and both are greater than the SPL of the Run 7. Specifically, the SPLs at the driving frequency $4 \mathrm{kHz}$ obtained using the design chart and the constrained optimization are increased by approximately 5 $\mathrm{dB}$ and $8.7 \mathrm{~dB}$, respectively, over the original Run 7 design. The SPL response at $4 \mathrm{kHz}$ of the constrained optimization design $(89.7 \mathrm{~dB})$ is higher than the design chart method $(85$ $\mathrm{dB}$ ) by $3.7 \mathrm{~dB}$. This result reveals that the SPL attainable at the driving frequency can be significantly increased over the preliminary design using the proposed optimization procedure. 
(a)

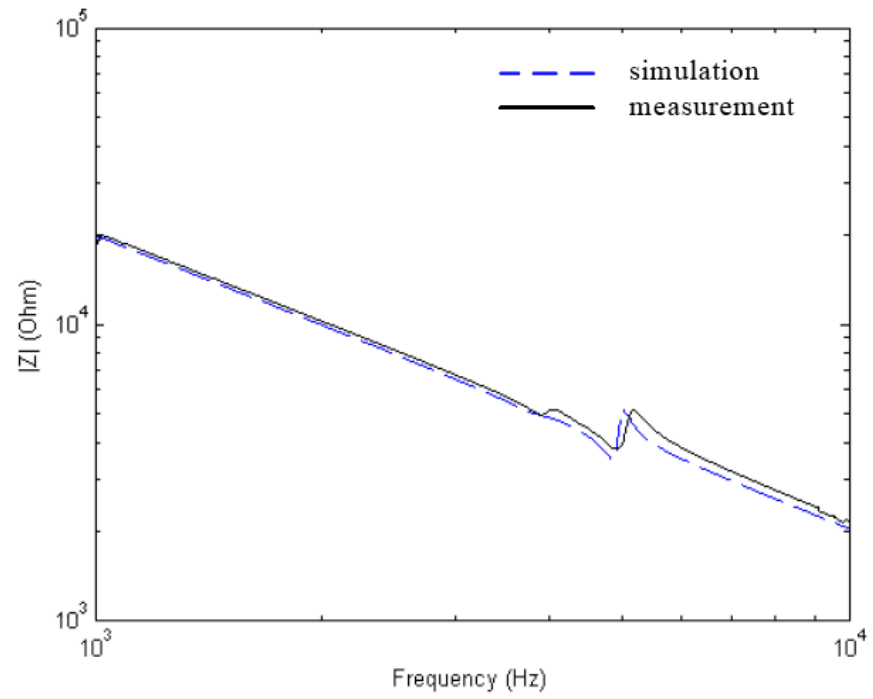

(b)

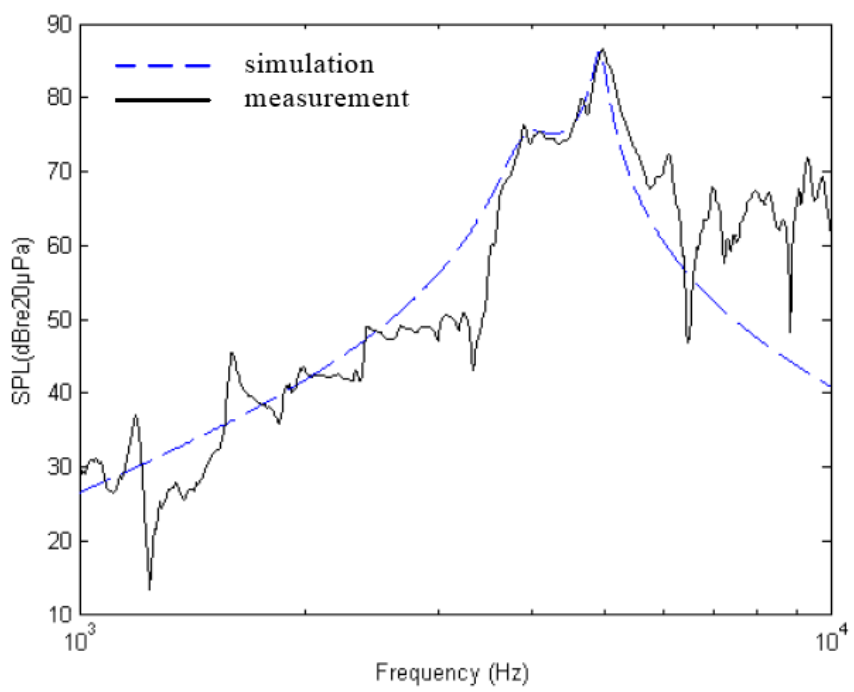

Fig. (17). Frequency responses of the piezoelectric buzzer obtained from the experiment and FEM simulation. (a) Electrical impedance, (b) on-axis SPL.

On the basis of the result of the $L_{9}\left(3^{4}\right)$ orthogonal array, sensitivity analysis is conducted to examine the effects of varying physical parameters on the lumped parameter. The result of sensitivity analysis is shown in Table 7, with the lumped parameters, $C_{0}, R_{1}, L_{1}, C_{1}, f_{m}, \phi$ and SPL indicated. The result of the analysis suggests that if one wishes to increase the SPL output of the piezoelectric diaphragm, he should increase the Young's modulus, the radius of PZT disc and the value of $d_{31}$.

\section{CONCLUSIONS}

A simulation technique based on FEM along with twoport models has been presented in this paper for piezoelectric buzzers. Finite element analysis has been exploited for modeling piezoelectric diaphragm. With added-mass parameter

Table 5. The Results of Piezoelectric Diaphragm Obtained Using Taguchi Method

\begin{tabular}{|c|c|c|c|c|c|c|c|c|c|}
\hline & Run 1 & Run 2 & Run 3 & Run 4 & Run 5 & Run 6 & Run 7 & Run 8 & Run 9 \\
\hline$C_{\mathrm{f}}$ & $9.35 \mathrm{E}-09$ & 7.42E-09 & $3.56 \mathrm{E}-09$ & 4.40E-09 & $1.16 \mathrm{E}-8$ & $9.17 \mathrm{E}-9$ & $1.10 \mathrm{E}-8$ & $5.28 \mathrm{E}-9$ & $1.39 \mathrm{E}-8$ \\
\hline$f_{\mathrm{p}}$ & 5320 & 5455 & 5725 & 5275 & 4982.5 & $4.69 \mathrm{E}+03$ & 4780 & 4690 & 4330 \\
\hline$f_{\mathrm{s}}$ & 5275 & 5365 & 5635 & 5140 & 4870 & 4600 & 4532.5 & 4600 & 4195 \\
\hline$C_{0}$ & $9.20 \mathrm{E}-09$ & $7.18 \mathrm{E}-09$ & $3.45 \mathrm{E}-09$ & $4.18 \mathrm{E}-09$ & $1.11 \mathrm{E}-8$ & $8.82 \mathrm{E}-9$ & $9.90 \mathrm{E}-9$ & $5.08 \mathrm{E}-9$ & $1.30 \mathrm{E}-8$ \\
\hline$C_{1}$ & $1.58 \mathrm{E}-10$ & $2.43 \mathrm{E}-10$ & $1.11 \mathrm{E}-10$ & $2.22 \mathrm{E}-10$ & $5.17 \mathrm{E}-10$ & $3.48 \mathrm{E}-10$ & $1.11 \mathrm{E}-9$ & $2.01 \mathrm{E}-10$ & $8.52 \mathrm{E}-10$ \\
\hline$L_{1}$ & 5.777 & 3.6229 & 7.177 & 4.3103 & 2.0675 & 3.4355 & 1.1102 & 5.9605 & 1.6885 \\
\hline$R_{1}$ & 7103.8 & 5058.2 & 11705 & 6201 & 2867.8 & 4213.5 & 1489.7 & 7114.3 & 2125.7 \\
\hline$R_{0}$ & $5.66 \mathrm{E} 7$ & 3.01E8 & $4.41 \mathrm{E} 7$ & $2.44 \mathrm{E} 7$ & $1.66 \mathrm{E} 7$ & $2.19 \mathrm{E} 8$ & $2.60 \mathrm{E} 7$ & $1.90 \mathrm{E} 7$ & $9.29 \mathrm{E} 6$ \\
\hline$Q$ & 26.954 & 24.144 & 21.709 & 22.448 & 22.06 & 23.565 & 21.223 & 24.215 & 20.937 \\
\hline$f_{\mathrm{m}}$ & 5117.5 & 5185 & 5275 & 4982.5 & 4712.5 & 4442.5 & 4420 & 4465 & 4060 \\
\hline$f_{\mathrm{m} \_ \text {add }}$ & 3542.5 & 3610 & 3700 & 3520 & 3160 & 3047.5 & 3160 & 3227.5 & 2957.5 \\
\hline$M_{\mathrm{m}}$ & $4.60 \mathrm{E}-5$ & $4.70 \mathrm{E}-5$ & $4.84 \mathrm{E}-5$ & $4.98 \mathrm{E}-5$ & $4.09 \mathrm{E}-5$ & $4.44 \mathrm{E}-5$ & $5.23 \mathrm{E}-5$ & 5.47E05 & $5.65 \mathrm{E}-5$ \\
\hline$C_{\mathrm{m}}$ & $2.10 \mathrm{E}-5$ & $2.00 \mathrm{E}-5$ & $1.88 \mathrm{E}-5$ & $2.05 \mathrm{E}-5$ & $2.79 \mathrm{E}-5$ & $2.89 \mathrm{E}-5$ & $2.48 \mathrm{E}-5$ & $2.32 \mathrm{E}-5$ & $2.72 \mathrm{E}-5$ \\
\hline$R_{\mathrm{m}}$ & 0.0192 & 0.0221 & 0.025 & 0.0242 & 0.0191 & 0.0183 & 0.024 & 0.0222 & 0.024 \\
\hline$\phi$ & 0.001643 & 0.0021 & 0.00146 & 0.002 & 0.00258 & 0.00208 & 0.004 & 0.00176 & 0.00336 \\
\hline SPL (dB)@ $1^{\text {st }}$ mode & 78.2213 & 79.1629 & 74.8686 & 77.5531 & 81.4373 & 79.4222 & 82.7982 & 76.4065 & 80.4534 \\
\hline
\end{tabular}


identification, the FEM model is converted into electromechanical two-ports ready for the construction of EMA analogous circuits. Electrical impedance and on-axis pressure response of the piezoelectric buzzer can be calculated by solving the loop equations on the simulation platform.

(a)

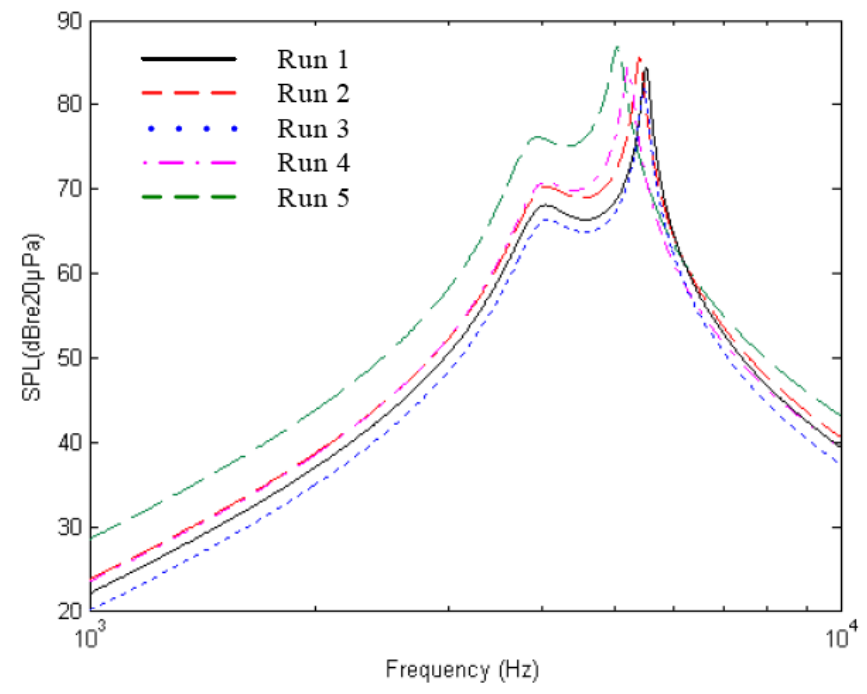

(b)

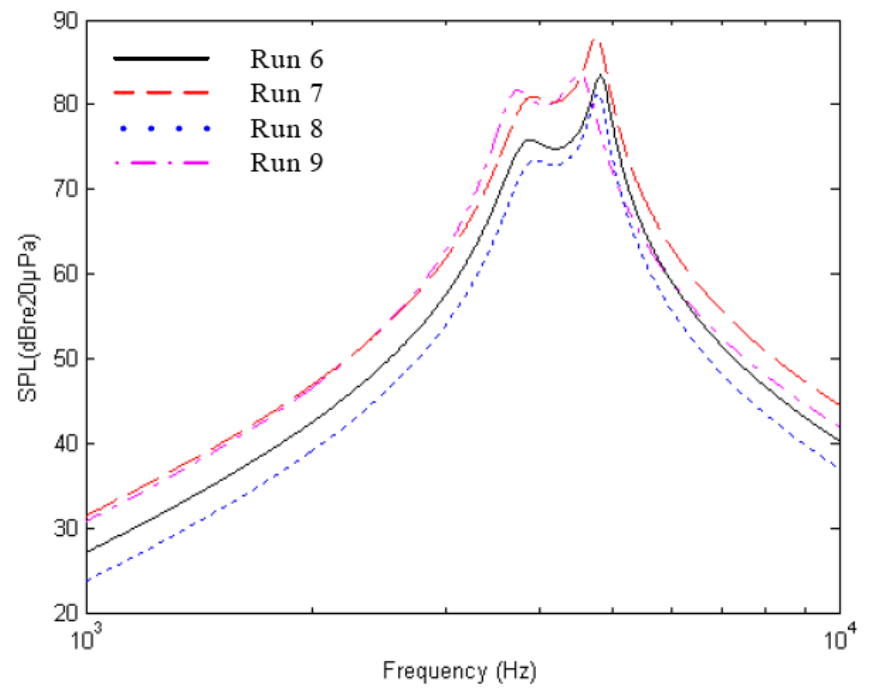

Fig. (18). The on-axis SPL of the piezoelectric buzzer obtained from the Taguchi method. (a) on-axis SPL for Taguchi 1-5 (b) onaxis SPL for Taguchi 6-9.

By taking advantage of the simulation platform, we have developed an optimization design procedure for the piezoelectric buzzer. A preliminary search for the feasible design is carried out using the Taguchi method. This feasible design serves as the initial setting for the following optimization procedures such as the design chart or constrained optimization. The result shows that constrained optimization yields higher SPL at the driving frequency than the design chart method.

Since the optimal design is expressed in terms of lumped parameters, the link between physical and lumped parame-

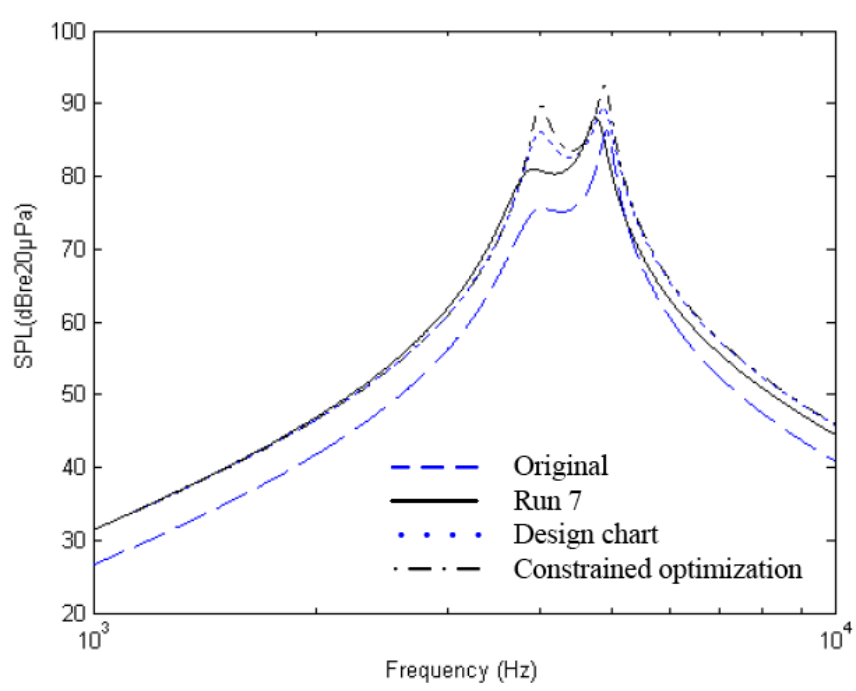

Fig. (19). Comparison of the on-axis SPLs obtained using the Taguchi 7 , the design chart and the constrained optimization.

Table 6. Results Obtained Using the Taguchi 7, the Design Chart and the Constrained Optimization

\begin{tabular}{|c|c|c|c|c|}
\hline Symbols & Original & Taguchi 7 & $\begin{array}{c}\text { Design } \\
\text { Chart }\end{array}$ & $\begin{array}{c}\text { Constrained } \\
\text { Optimization }\end{array}$ \\
\hline \hline$a_{p}(\mathrm{~m})$ & 0.001065 & 0.001065 & 0.0014 & 0.00202 \\
\hline$t_{c}(\mathrm{~m})$ & 0.00076 & 0.00076 & 0.0015 & 0.0038 \\
\hline$d_{A F}(\mathrm{~m})$ & 0.00308 & 0.00308 & 0.00308 & 0.0033 \\
\hline$C_{A F}\left(\mathrm{~m}^{5} / \mathrm{N}\right)$ & $1.8262 \mathrm{e}-12$ & $1.8262 \mathrm{e}-12$ & $1.8262 \mathrm{e}-12$ & $2.01083 \mathrm{e}-12$ \\
\hline$M_{A P}\left(\mathrm{~kg} / \mathrm{m}^{4}\right)$ & 786.8065 & 786.8065 & 701 & 641 \\
\hline$R_{A P}\left(\mathrm{~N} . \mathrm{s} / \mathrm{m}^{5}\right)$ & $3.31 \mathrm{e} 6$ & $3.31 \mathrm{e} 6$ & $2.16 \mathrm{e} 6$ & $1.29 \mathrm{e} 6$ \\
\hline$\rho$ & 0.0513 & 0.0515 & 0.0458 & 0.0419 \\
\hline$f_{\mathrm{m}}(\mathrm{Hz})$ & 4812.44 & 4420 & 4420 & 4420 \\
\hline$f_{\mathrm{a}}(\mathrm{Hz})$ & 4145 & 4145 & 4392 & 4432 \\
\hline$\alpha$ & 1.1597 & 1.066 & 1.006 & 0.997 \\
\hline$\phi$ & 0.0032 & 0.004 & 0.004 & 0.004 \\
\hline $\mathrm{SPL}(\mathrm{dB})$ & 74.7 & 81 & 86 & 89.7 \\
\hline
\end{tabular}

ters should be appreciated. To facilitate the interpretation of the optimal design, sensitivity analysis is conducted for exploring the effects of varying physical parameters of piezoelectric diaphragm on the lumped parameters. The results summarized in Table 5 provide useful guidelines of how to 'tune' physical parameters in practical design, given the optimized lumped parameters.

\section{ACKNOWLEDGEMENTS}

The work was supported by China Steel Corporation and the National Science Council in Taiwan, Republic of China, under the project number NSC 95-2221-E-009-009-MY2. 
Table 7. The Results of Sensitivity Analysis. M Represents 'Major' Influence, m Represents 'Minor' Influence, $\uparrow$ Represents 'Increase', $\downarrow$ Represents 'Decrease', and - Represents 'Unchanged'

\begin{tabular}{|c|c|c|c|c|}
\hline & \multicolumn{3}{|c|}{ PZT Diaphragm } & Metal Plate \\
\cline { 2 - 5 } & Radius $\uparrow$ & $d_{31}$ Value $\uparrow$ & Density $\uparrow$ & Young's Modulus $\uparrow$ \\
\hline \hline$C_{0} \uparrow$ & $\uparrow(\mathrm{M})$ & $\uparrow(\mathrm{M})$ & - & - \\
\hline$C_{1} \uparrow$ & $\uparrow(\mathrm{M})$ & $\uparrow(\mathrm{m})$ & - & - \\
\hline$L_{1} \uparrow$ & $\downarrow(\mathrm{m})$ & $\downarrow(\mathrm{M})$ & - & $\downarrow(\mathrm{m})$ \\
\hline$R_{1} \uparrow$ & $\downarrow(\mathrm{M})$ & $\downarrow(\mathrm{M})$ & $\uparrow(\mathrm{m})$ & $\downarrow(\mathrm{m})$ \\
\hline$f_{\mathrm{m} \uparrow}$ & $\downarrow(\mathrm{M})$ & $\downarrow(\mathrm{m})$ & $\downarrow(\mathrm{m})$ & $\uparrow(\mathrm{M})$ \\
\hline$\phi \uparrow$ & $\uparrow(\mathrm{M})$ & $\uparrow(\mathrm{M})$ & $\uparrow(\mathrm{m})$ & - \\
\hline $\mathrm{SPL} \uparrow$ & $\uparrow(\mathrm{M})$ & $\uparrow(\mathrm{M})$ & $\uparrow(\mathrm{m})$ & - \\
\hline
\end{tabular}

\section{REFERENCES}

[1] Caliano G, Lamberti N, Iula A, Pappalardo M. A piezoelectric bimorph static pressure sensor. Sens Actuators A 1995; 46: 176178 .

[2] Tseng CI, Liou WJ. Simulation of a bimorph transducer under acoustic excitation. Comput Struct 1996; 59: 141-148.

[3] Dobrucki AB, Pruchnicki P. Theory of piezoelectric axisymmetric bimorph. Sens Actuators A 1997; 58: 203-212.

[4] Wang Q, Quek ST, Sun CT, Liu X. Analysis of piezoelectric coupled circular plate. Smart Mater Struct 2001; 10: 229-239.

[5] Wang BT, Chen PH, Chen RL. Finite element model verification for the use of piezoelectric sensor in structural modal analysis. Chin J Mechan 2006; 22: 107-114.
[6] Lim YH. Finite-element simulation of closed loop vibration control of a smart plate under transient loading. Smart Mater Struct 2003; 12: $272-286$

[7] Guo N, Cawley P. Measurement and prediction of the frequency spectrum of piezoelectric disks by modal analysis. J Acoust Soc Am 1992; 92(9): 3379-3388.

[8] Aronov B. The energy method for analyzing the piezoelectric electroacoustic transducers. J Acoust Soc Am 2005; 117: 210-220.

[9] Aronov B. The energy method for analyzing the piezoelectric electroacoustic transducers II. (With the examples of the flexural plate transducer). J Acoust Soc Am 2005; 118: 627-637.

[10] Bai MR, Lu Y. Optimal implementation of miniature piezoelectric panel speakers using the Taguchi method and Genetic algorithm. J Vibrat Acoust 2004; 126: 359-369.

[11] Wen FL, Mou SC, Ouyang M. Design and construction of shaftdriving type piezoceramic ultrasonic motor. Ultrasonics 2004; 43 : $35-47$.

[12] Caronti A, Caliano G, Pappalardo M. An accurate model for capacitive micromachined ultrasonic transduers. IEEE Trans Ultrason Ferroelectrics Frequency Control 2002; 49: 159-168.

[13] Gallas Q, Holman R, Nishida T, Carroll B, Sheplak M, Cattafesta L. Lumped element modeling of piezoelectric-driven synthetic jet actuators. AIAA J 2003; 41: 240-247.

[14] Bai MR, Chen RL, Chuang CY. Optimal design of resonant piezoelectric buzzer from a perspective of vibration-absorber theory. J Acoust Soc Am 2007; 122(3): 1568-1580.

[15] Leach WM Jr. Introduction to Electroacoustics and Audio Amplifier Design, Kendall-Hunt, Dubuque, IA, 2003.

[16] Beranek LL. Acoustics, Acoustical Society of America, Woodbury, 1996.

[17] Desoer CA, Kuh ES. Basic Circuit Theory, McGraw-Hill, New York, 1969.

[18] Hicks CR, Turner KV. Fundamental concepts in the design of experiments, Oxford University Press, 1999.

[19] Swanson Analysis Systems (ANSYS), Ann Arbor, MI, 1998, (http://www.ansys.com/)

[20] IEEE, IEEE Standard on Piezoelectricity, IEEE, New York, 1987.

[21] Math Works, Matlab optimization toolbox, Natick, Mass, (http://www.mathworks.com/products/ optimization/).

(C) Bai et al.; Licensee Bentham Open.

This is an open access article distributed under the terms of the Creative Commons Attribution License (http://creativecommons.org/licenses/by/2.5/), which permits unrestrictive use, distribution, and reproduction in any medium, provided the original work is properly cited. 